\title{
Un asentamiento de época púnica en la campiña costera de la Bahía de Cádiz. Estructuras, fases de uso y contextos materiales de Puerto-19
}

\section{A Punic settlement in the coastal countryside of the Bay of Cadiz. Structures, main phases and material contexts at Puerto-19}

\author{
Antonio M. Sáez Romero ${ }^{1}$ \\ Universidad de Sevilla \\ José María Gutiérrez López² \\ María Cristina Reinoso del Río ${ }^{3}$ \\ Museo Histórico Municipal de Villamartín
}

\begin{abstract}
RESUMEN
Entre los años 1996-1997 diversas actuaciones de urgencia dieron como resultado la excavación de los principales componentes de un saladero púnico de pescado situado en la zona de Pinar Hondo de la localidad gaditana de El Puerto de Santa María. Los resultados de estas intervenciones fueron posteriormente dados a conocer de forma preliminar, proporcionando una visión parcial de las características de las estructuras y materiales de Puerto-19. El estudio de los materiales recuperados en dichas excavaciones durante los años 2008-2010 ha permitido revisar estas primeras propuestas y definir una nueva secuencia de evolución del asentamiento, además de caracterizar con más detalle los componentes materiales de sus diversas fases de vida. A lo largo de tres fases principales, el enclave evolucionó desde la segunda mitad del siglo VI hasta las últimas décadas del III a. C. desde un saladero de pescado (Edificio A) hasta una construcción probablemente multifuncional (Edificio B), seguramente abandonada antes de la conquista romana de la zona en relación con la II Guerra Púnica.
\end{abstract}

\section{SUMMARY}

During 1996-1997 several rescue excavations resulted in the discovery of the main components of a Punic fish-salting facility located in the area of Pinar Hondo in the current city of El Puerto de Santa María (Cadiz, Spain). The results of the

${ }^{1}$ asaez1@us.es / ORCID iD: https://orcid.org/0000-00017071-9748

2 museomunicipal@villamartin.es / ORCID iD: https://orcid. org/0000-0001-5257-0556

3 museovillamartin@hotmail.com / ORCID iD: https://orcid. org/0000-0003-2910-8309 excavations were subsequently released in some preliminary reports that only featured a partial picture of the characteristics of the main structures and contexts of Puerto-19. The study of the items recovered (pottery, fishing gear, faunal remains, etc.) through 2008-2010 has made possible to review the first hypotheses and develop a new scheme of the evolution of the rural site, and as well to complete a deeper characterization of the material assemblages linked to the successive stratigraphic phases. Throughout three main stages, the settlement evolved from the second half of the 6th century until the last decades of the 3rd century BCE from a fish-processing facility (Building A) to a multifunctional structure (Building B), probably abandoned before the Roman conquest of the area during the Second Punic War.

PALABRAS CLAVE: Gadir; salazón; pesca; ánforas; vino.

KEY WORDS: Gadir; fish-processing; fishing; amphorae; wine.

CÓMO CITAR ESTE ARTÍCULO / CITATION: Sáez Romero, A. M., Gutiérrez López, J. M. y Reinoso del Río, M. C. 2020: "Un asentamiento de época púnica en la campiña costera de la Bahía de Cádiz. Estructuras, fases de uso y contextos materiales de Puerto-19", Archivo Español de Arqueología 93, 61-80. https://doi.org/10.3989/ aespa.093.020.003

\section{INTRODUCCIÓN}

El papel del comercio marítimo, de la pesca y de la fabricación de conservas de pescado fue crucial para la economía de la bahía gaditana en la Antigüedad, y por ello ha sido un hito de referencia recurren-

Copyright: ( 2020 CSIC. Este es un artículo de acceso abierto distribuido bajo los términos de una licencia de uso y distribución Creative Commons Reconocimiento 4.0 Internacional (CC-by 4.0). 
te desde la etapa erudita de la Edad Moderna hasta los más recientes estudios de inicios del siglo XXI. La existencia de menciones explícitas a esta fuente de riqueza en los pocos textos antiguos referidos a este rincón atlántico, su presencia protagonista entre los tipos monetales de la ceca ciudadana y, en menor medida, el descubrimiento ocasional de restos de piletas y ánforas, habían consagrado, desde momentos muy iniciales de la investigación a esta temática, como un topos historiográfico. La irrupción en este escenario de la Arqueología científica contemporánea no ha hecho sino acrecentar y perfilar las referencias disponibles hasta entonces. La proliferación de actuaciones sistemáticas y de urgencia desde los primeros años ochenta despertó de nuevo a este gigante historiográfico, adormilado por varias décadas de decaimiento general del interés por el pasado de la zona, resurgiendo con gran fuerza hasta colocarse en los inicios de la presente centuria de nuevo como una de las principales líneas de investigación sobre la ciudad de Gadir/ Gades (Sáez 2010).

A pesar de que en pocas décadas por fin se habían identificado y excavado los centros que produjeron las salazones y las ánforas citados en las fuentes clásicas y se habían publicado múltiples avances o síntesis preliminares sobre la "industria pesqueroconservera" gaditana, resultaba tremendamente sorprendente que tal acumulación de esfuerzos no hubiera dado el fruto deseable de una memoria final de alguna de las excavaciones llevada a cabo en los yacimientos considerados como saladeros. Así, gran parte de las hipótesis alumbradas sobre estos temas estaban basadas en informaciones preliminares y palimpsestos históricos. En el caso de los indicios disponibles para la costa noreste de la bahía, entre los ríos Salado y Guadalete, los yacimientos localizados dibujaban además un mapa de compleja interpretación cuyo papel en conjunto -al igual que los propios yacimientos individualmente- era de difícil encaje con el modelo territorial gadirita (García y Ferrer 2001; Ferrer 2007), debiendo basarse las interpretaciones en hallazgos de superficie (Ruiz Gil 1991) y en los datos parciales dados a conocer sobre la "factoría" de Las Redes (Frutos et alii 1988; Muñoz et alii 1988; Frutos y Muñoz 1996).

El inicio de la redacción de la tesis doctoral de uno de los firmantes ${ }^{4}$ y nuestro convencimiento de que era necesario poner fin a estos déficits, al menos en casos destacados, llevaron a desarrollar la idea de acometer

${ }^{4}$ Antonio M. Sáez Romero, "Alfares y saladeros de Gadir. Una aproximación arqueológica a la economía conservera de la Bahía de Cádiz en época púnica y tardopúnica (siglos-VI a-I)”. Tesis Doctoral, Universidad de Cádiz, 2014. el estudio de los resultados de las excavaciones efectuadas en 1996-1997 del saladero portuense de Puerto-19, que habían sido dados a conocer brevemente por su primer excavador (Gutiérrez 2000, 2001 y 2004). Por ello se solicitó en el año 2008 el estudio de los materiales depositados en el Museo Municipal de El Puerto de Santa María ${ }^{5}$, prolongándose los trabajos de documentación gráfica y análisis hasta 2010.

Inicialmente el propósito fue completar la documentación de campo y fijar las fases crono-estratigráficas definitivas del yacimiento, dando lugar a la publicación de una memoria definitiva sobre los trabajos. Al mismo tiempo, el estudio se orientó hacia la mencionada necesidad de subsanar la ausencia del análisis empírico de uno de estos establecimientos conserveros púnico-gadiritas, proporcionando a los investigadores un primer cimiento -completo y contextualizado-, a través del cual fuese posible reconsiderar las hipótesis en vigor. De este modo, se presenta un avance de los resultados del proyecto, que verán la luz de forma más amplia en una monografía coordinada por los autores, en colaboración con el resto de especialistas citados. Se aportan en esta síntesis las principales conclusiones extraídas tras completar el proceso de reestudio de los materiales y de la secuencia de Puerto-19, que ha dado como consecuencia una nueva lectura de sus fases arqueológicas, la caracterización de los horizontes materiales y la realización de analíticas arqueométricas (radiocarbono), arqueozoológicas (fauna marina y terrestre) y complementarias (epigrafía púnica). Esta nueva documentación, ordenada contextualmente, ha permitido asimismo revisar la dinámica vital de los asentamientos secundarios detectados en la campiña portuense entre la etapa colonial y la integración en el mundo romano, de lo cual también se proporciona un breve anticipo.

${ }^{5}$ La investigación sobre los materiales de Puerto-19 no habría podido hacerse sin la necesaria ayuda y amabilidad de diversas personas e instituciones. En especial, nos gustaría agradecer la positiva disposición y la asistencia logística suministrada por el Museo Municipal de El Puerto de Santa María, donde se encuentran depositados los materiales procedentes de las excavaciones en el yacimiento, y particularmente la labor de Francisco Giles Pacheco, Juan José López Amador y Javier de Lucas Almeida en los meses de trabajo de documentación gráfica. M. ${ }^{a}$ Carmen Blanes Delgado, directora de la intervención de 1997, accedió gentilmente a la inclusión en el estudio general del registro recuperado en la actuación de su responsabilidad. Tampoco queremos dejar de reconocer el apoyo brindado por Javier Maldonado Rosso y Miguel Ángel Caballero desde el área de Patrimonio del Ayuntamiento de El Puerto de Santa María. Es necesario subrayar la decisiva contribución de los colegas que han permitido completar el estudio de los materiales, José Á. Zamora López (epigrafía fenicia), José A. Riquelme Cantal (fauna terrestre), Milagrosa C. SoriguerEscofet (fauna marina) y Guillem Pérez Jordà (arqueobotánica). 


\section{PUERTO-19: SECUENCIA ARQUEOLÓGICA, MATERIALES Y CRONOLOGÍA}

Los comienzos de la investigación sobre Puerto-19 pueden rastrearse desde la identificación inicial de los asentamientos prerromanos diseminados por el término municipal de El Puerto de Santa María, incluyéndose en el listado inicial resultado de las prospecciones del museo municipal a inicios de la década de los ochenta del pasado siglo. El yacimiento fue posteriormente sondeado en 1986 en otra campaña de prospecciones dirigida por J. A. Ruiz Gil (1987), con resultados positivos pero muy incompletos y de compleja interpretación, lo que ayudó a que la localización pasara "parcialmente desapercibida" durante las primeras etapas de la investigación, diluida entre la masa de enclaves ubicados en la costa continental. Su emergencia en la historiografía como punto de referencia no acontecería hasta las actuaciones preventivas de 1996-1997 y la difusión de algunos trabajos de síntesis preliminares por parte de su excavador (Gutiérrez 2000, 2001 y 2004). Con posterioridad han sido escasos los trabajos que han aportado novedades, excepto breves referencias a algunos materiales significativos relacionados con las artes pesqueras (Gutiérrez y Giles 2004) o su inclusión como ejemplo destacado entre el catálogo de "saladeros de pescado" gadiritas (Sáez 2011, 2014).

Respecto a la interpretación funcional y de la secuencia del asentamiento, posteriores referencias han aportado apenas pequeños destellos en forma de análisis de restos vegetales de algunos contextos (López y Ruiz 2007), mientras que en general se ha venido citando, reproduciendo y reelaborando la información aportada por su excavador (Ruiz et alii 2006; Bernal y Sáez 2007; Muñoz y Frutos 2009). Posiblemente el hecho de que solo se dispusiese de una publicación parcial de los resultados secuenciales y planimétricos ha contribuido a forjar una imagen estereotipada del yacimiento y de su problemática específica, quizá excesivamente condicionada por la información procedente de otros sitios cercanos como Las Redes, igualmente solo conocidos gracias a informaciones preliminares. El crecimiento del interés por los temas referidos a la pesca y las conservas piscícolas en la última década había llevado la situación historiográfica del yacimiento a un extremo alarmante, lanzándose hipótesis interpretativas carentes de un verdadero apoyo analítico contextual, ya que en ningún momento se habían acometido desde la base proporcionada por un examen directo de los materiales o la ejecución de una verdadera memoria de las excavaciones (López y Ruiz 2007).

Por esta razón, decidimos completar el estudio integral de los restos de las diversas campañas de ex- cavación. Así, tanto estructuras como materiales han podido ser reevaluados en su conjunto, planteando sugerentes matices a la secuencia de uso/abandono industrial propuesta inicialmente. Como ejemplo de esta actualización, los conjuntos materiales han sido tratados ahora de una forma exhaustiva, procesándose casi un millar de objetos diagnosticables a nivel gráfico y estadístico, además de una gran cantidad de fauna, sobre todo malacológica. Esto permite ahora hablar con sólidos fundamentos acerca de las características del modelo productivo desarrollado, de las fases arqueológicas -con dataciones precisas-, y de la composición del mobiliario empleado por los trabajadores para las labores pesquero-conserveras, comerciales, de su propio mantenimiento y consumo cotidiano.

\section{I. LAS FASES DE OCUPACIÓN DEL YACIMIENTO: VIEJAS Y NUEVAS INTERPRETACIONES}

Apenas finalizados los trabajos de campo de 1996, el informe preliminar de la intervención ya estableció una superposición de vertidos, fosas y edificios que fue reconocida rápidamente como los restos de un centro de producción conservera de época feniciopúnica, formulándose una primera propuesta de interpretación de la secuencia dividida en tres horizontes de ocupación principales. Así, de inmediato se planteó por parte de su excavador la existencia de una secuencia compleja e ininterrumpida durante varias centurias, subrayándose el protagonismo de los vestigios de tipo conservero al menos en las dos fases más recientes. Los avances en el procesamiento de la documentación permitieron poco tiempo después matizar esta propuesta inicial, añadiendo nuevos ingredientes de interés para el análisis del saladero, partiendo de la premisa de una prolongada y reiterada ocupación industrial que reutilizó frecuentemente los restos de las etapas precedentes, hasta un momento terminal del siglo III o los inicios del II a. C. (Gutiérrez 2000: 2021, 2001: 80, 2004: 246-247). Se proporcionaba asimismo una información algo más extensa y afinada sobre los materiales característicos de cada una de estas fases, destacando la publicación de elementos de vajilla engobada, ánforas locales e importadas, o incluso un sello alfarero mostrando un prótomo de caballo (Gutiérrez 2000).

En el año 2008 planteamos la necesidad de continuar con la investigación no solo de la campaña de 1996 sino del conjunto de actividades arqueológicas llevadas a cabo en el yacimiento (Fig. 1), intentando así superar los estadios preliminares en que nos encontrábamos a nivel de informes y publicaciones. Los 


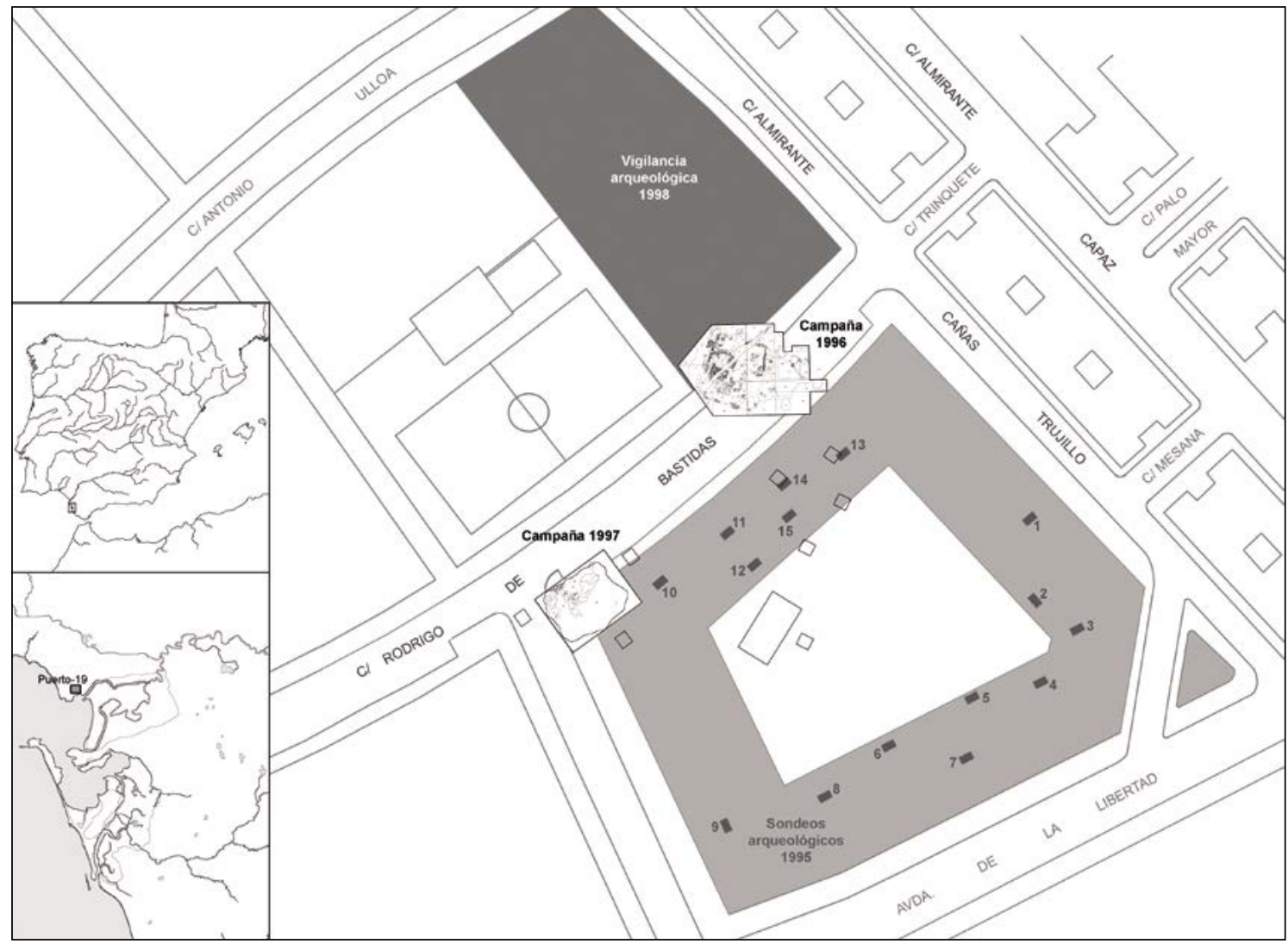

Figura 1. Situación en el parcelario actual de las sucesivas intervenciones desarrolladas en el área de Pinar Hondo, que conllevaron la excavación integral de Puerto-19. Además de las zonas principales excavadas en 1996-1997, se indica la localización de los sondeos preliminares de 1995 (puntos grises numerados) y de la parcela sujeta a vigilancia arqueológica en 1998 (sombreada en gris oscuro). Ubicación de la zona en un plano actual de la Bahía de Cádiz (elaboración propia).

resultados del estudio de los materiales y del examen de las asociaciones estratigráfico-contextuales documentadas en los trabajos de campo de 1996-1997 han permitido la reinterpretación de la secuencia del saladero, planteándose una nueva hipótesis reconstructiva de la evolución de sus estructuras y horizontes materiales asociados en torno a cinco fases:

- Fase 0: Momento previo a la ocupación feniciopúnica, sin evidencias antrópicas de época prehistórica, y que por tanto básicamente se encuentra representada por una potente formación dunar compactada que es la base geológica de toda la zona (Borja et alii 1997).

- Fase I: El uso industrial de la zona se iniciaría en época tardoarcaica (Fase I), con dos procesos diferenciados consecutivos que en realidad pertenecerían a un mismo momento histórico: una "subfase fundacional" con la realización de un pequeño ritual (Fase I-a) y la erección y uso del complejo edilicio A en la parte alta de la duna (Fase I-b).
El asentamiento se fundó en algún momento de la segunda mitad o último tercio del siglo VI a. C. en una zona elevada cercana a la antigua línea de costa (Fig. 2). Este momento inaugural (Subfase I-a) ha podido ser bien caracterizado debido a la presencia de fosas con cenizas y abundantes restos cerámicos situadas bajo las estancias principales del complejo, quizá fruto de prácticas rituales fundacionales. A este momento pertenece un pequeño pavimento de conchas situado bajo las piletas principales (Fig. 3), que parece enfatizar este carácter ritual del momento de creación de las instalaciones industriales (Escacena y Vázquez 2009). Sobre estas fosas se construyó un edificio (A) de planta cuadrada dotado de varios espacios (Subfase I-b), uno de ellos reservado a una pareja de piletas ovaladas, con un gran patio descubierto en el que se almacenaban envases anfóricos quizá listos para ser rellenados. Además se localizaron pequeñas fosas o acumulaciones de materiales relacionadas con las labores artesanales y de consumo de los trabajadores del 
saladero. Esta etapa I-b habría finalizado circa 425/400 a. C. con el abandono del complejo conservero.

Los contextos asociados a esta subfase I-b proporcionaron abundantes restos cerámicos, especialmente ánforas locales del tipo T-11213 relacionadas con el

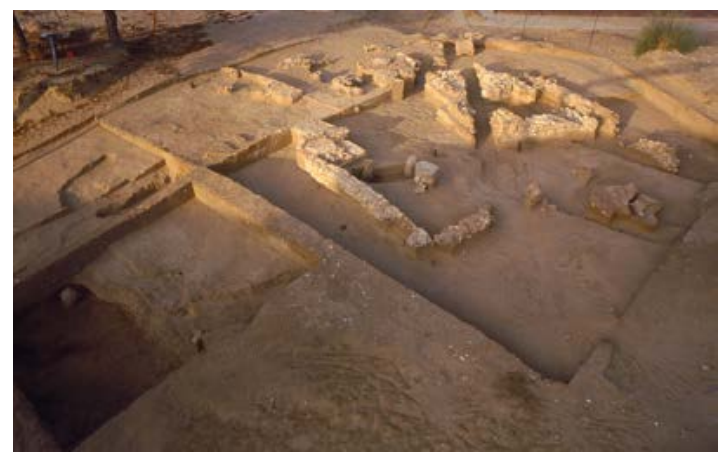

Figura 2. Vista general de la factoría conservera de Puerto-19 con las dos estructuras edilicias de la Fase III del saladero: estructura B en un primer plano y A (Fotografía J. M. ${ }^{a}$ Gutiérrez López).

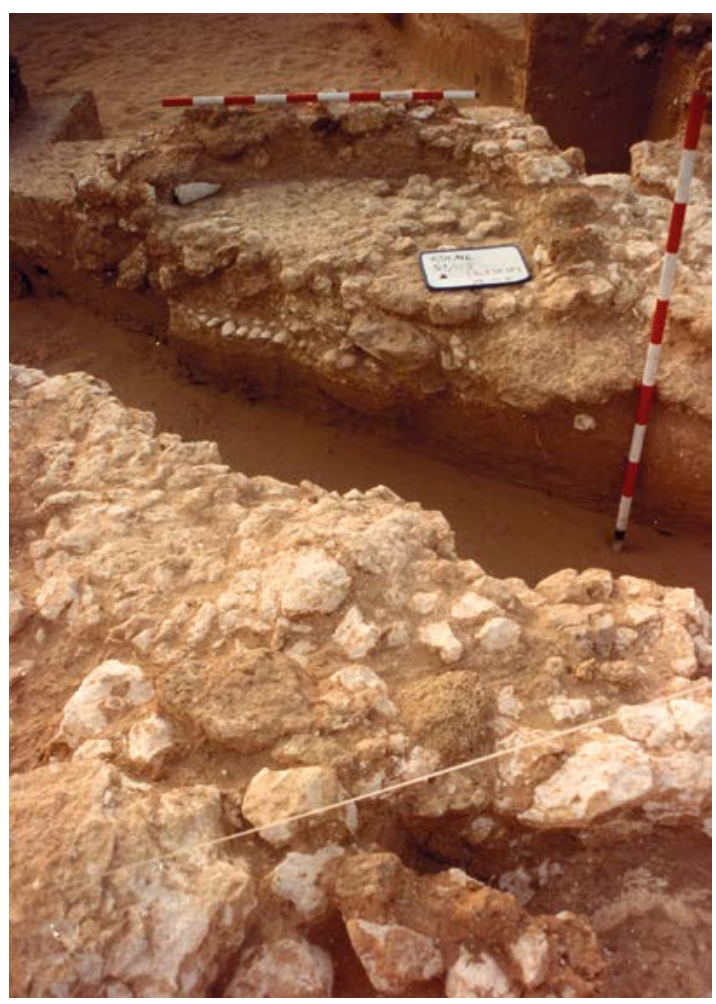

Figura 3. Pileta 1 en el edificio A. Superposición de la cubeta estanca sobre el pavimento de conchas de tipo Glycimerys (Fotografía J. M. a Gutiérrez López). transporte de salazones, así como algunos elementos relacionados con las artes pesqueras empleadas y restos de vajilla vinculada a los procesos de consumo. Buena parte de estos materiales se documentó en el Sector 2 de la campaña de 1997, una "zona de trabajo" cercana al edificio principal de la factoría, caracterizada por una gran área pavimentada con arcilla apisonada sobre la duna, rodeada de acumulaciones de materiales cerámicos y orgánicos. Hay que destacar que el examen de esta zona anexa ha permitido reinterpretar hallazgos como los registrados en Puerto-14, originalmente considerados asentamientos aislados de menor entidad o de carácter estacional (Ruiz Gil 1987; Ruiz et alii 2006). A la luz de la evidencia proporcionada por P-19, este tipo de yacimientos quizá puedan ser identificados con "zonas de trabajo" anexas a complejos edilicios industriales del tipo del Edificio A, algo también documentado en otros puntos de la bahía (Sáez Romero 2011, 2014).

- Fase II: Sobre los restos del primer edificio, se construyó uno nuevo (B) más pequeño, con una orientación diferenciada, también dotado de planta rectangular y probablemente de una pareja de piletas (Fig. 4). Las fosas de vertido habrían crecido en número por todo el perímetro de la factoría, afectando a las estructuras precedentes, especialmente los rebordes del Edificio A. Probablemente en estos momentos habría iniciado su actividad la gran área de vertidos localizada en las cotas descendentes de la parte oriental de la duna, donde parecen entremezclarse elementos de uso cotidiano e industriales. La cronología tanto de erección como de abandono de esta segunda fase edilicia del complejo resulta compleja de establecer debido a las interacciones estratigráficas con fosas posteriores, que apenas han dejado testimonios in situ, pero parece que la actividad ligada al edificio B podría haber cubierto parte del siglo IV y el tramo inicial del III a. C.

- Fase III: La última fase de actividad industrial se reduce arqueológicamente a la constatación de la ruina del Edificio B -parcialmente arrasado y cortado por el vertedero UE 126-, y la continuidad de diversas zonas de vertidos, quizá como fruto de la reutilización de las antiguas infraestructuras, abandonándose definitivamente el lugar hacia mediados o en algún momento de la segunda mitad del siglo III a. C. Son escasos los elementos de juicio disponibles, pero los materiales asociados a estos vertederos sugieren que ambas fases (II y III) debieron ser prácticamente consecutivas. Las características estructurales y la envergadura del asentamiento en este lapso no han podido determinarse en función de los restos exhumados, debido principalmente a la pérdida de documentación por el arrasamiento parcial de los niveles superiores por la dinámica urbana contemporánea. Ni siquiera 


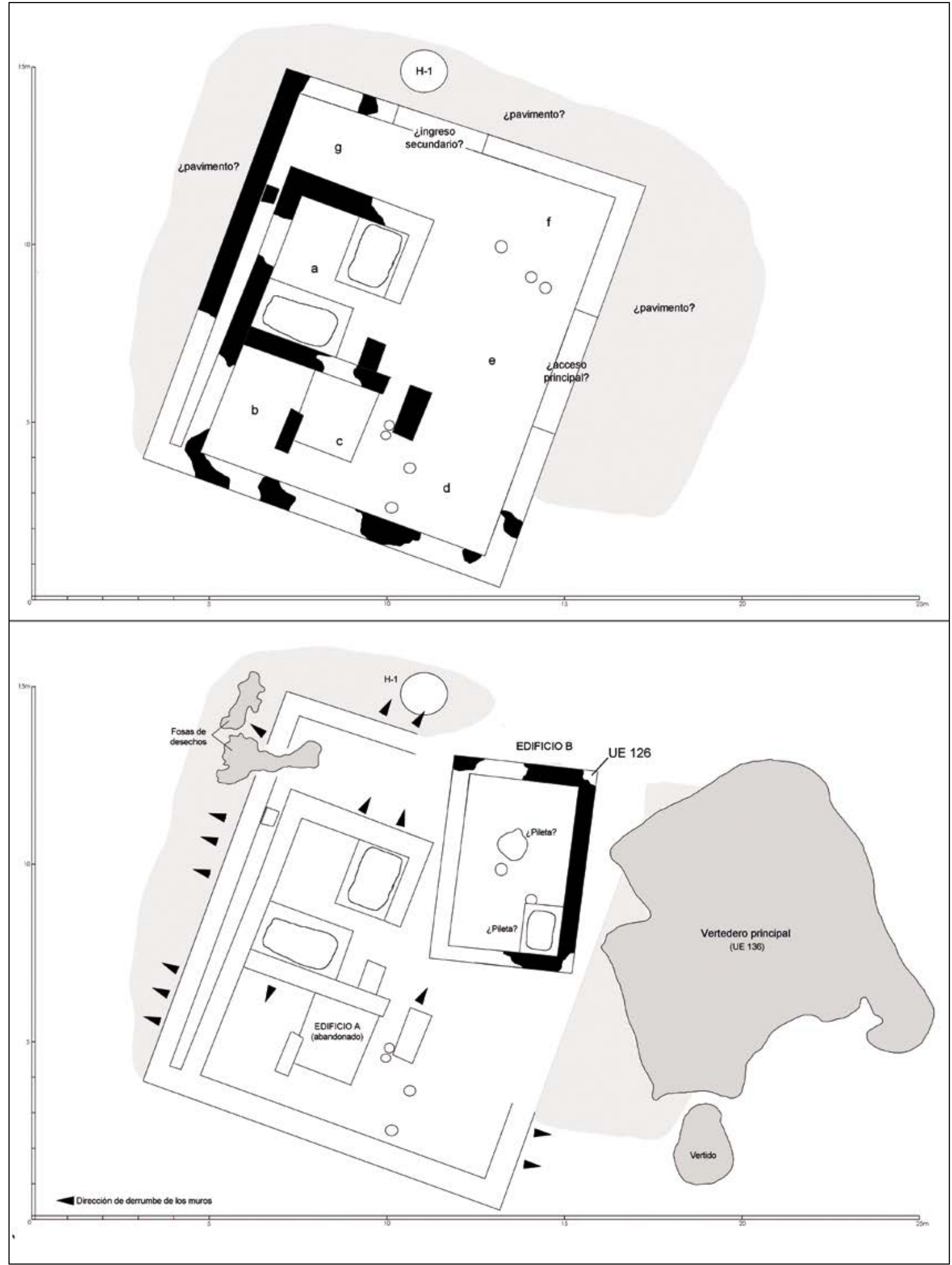

Figura 4. Planimetrías esquemáticas que muestran las dos fases principales del yacimiento, obtenidas a partir de la documentación original de campo. Arriba, Fase I-b (siglo V a. C.), abajo Fase II (siglos IV-III a. C.) de Puerto-19 (elaboración propia). 
elementos residuales recuperados en otros puntos de estos solares permiten alargar la fecha de finalización de la actividad púnica más allá de la horquilla propuesta.

Cabe apuntar, en relación con las transformaciones acaecidas en el asentamiento en las fases II-III, que los análisis complementarios realizados a restos de semillas de vitis vinifera ${ }^{6}$ documentados en diversos contextos -entre ellos el interior de una versión temprana de ánfora turdetana del tipo Pellicer D de la Fase II-, así como la existencia de posibles podones de hierro, permiten sospechar que al menos en este periodo el complejo habría podido desarrollar un rol multifuncional según el cual además de a las salazones de pescado Puerto-19 también habría podido estar dedicado a actividades agropecuarias. El análisis de los restos faunísticos asociados a estas fases parece apoyar la presencia habitual de una pequeña cabaña de ovicápridos, así como otros animales domésticos asociados a tareas complementarias (cánidos).

- Fase IV: La última fase arqueológica corresponde a los niveles de duna de formación eólica que sellaron los restos del complejo tras su abandono, y que han caracterizado el paraje de Pinar Hondo hasta su urbanización. El examen de los materiales y la documentación de campo no proporcionó dato positivo alguno acerca de actividades antrópicas posteriores al abandono tardo-púnico, pero la batería de dataciones radiométricas efectuada sugiere la posibilidad de una frecuentación en época medieval islámica (siglos IX$\mathrm{X}$ ), sin duda muy puntual, quizá ligada a un aprovechamiento agropecuario de estos suelos.

\subsection{LOS CONTEXTOS MATERIALES Y EL ESTABLECIMIENTO DE LA CRONOLOGÍA}

El procesado integral de los materiales ha permitido matizar las hipótesis crono-secuenciales de partida y ha ayudado decisivamente al establecimiento de la propuesta de fases, aportando argumentos cronológicos inadvertidos en acercamientos preliminares.

\footnotetext{
${ }^{6}$ El estudio carpológico fue desarrollado por el Dr. G. Pérez Jordá (Universidad de Valencia y CSIC) con anterioridad al inicio de nuestras tareas de reestudio del yacimiento, siendo avanzados algunos de sus datos en un trabajo de síntesis reciente sobre evidencias del cultivo de la vid en la Antigüedad en el área portuense (López y Ruiz Gil 2007). Anteriormente la presencia de vitis en la zona se había puesto de manifiesto en niveles arcaicos de Castillo de Doña Blanca (Roselló y Morales 1994), siendo bien conocida la existencia de lagares con piletas en los siglos IV-III a. C. (Ruiz Mata 1995 y 2018), por lo que la atestación de evidencias de su cultivo en P-19 debe insertarse en una dinámica de largo arraigo de manufactura local y consumo de vino y derivados de la uva (Niveau de Villedary 2011).
}

Esto ha sido especialmente significativo en el caso de la definición del momento inicial del yacimiento y también de su ocaso, en ambos casos ligados a elementos tanto anfóricos como de vajilla -engobe rojo y cerámicas "tipo Kuass"-, respectivamente.

La Subfase I-a, es decir, el momento fundacional del complejo, proporcionó una cantidad reducida de elementos diagnósticos pero cronológicamente muy significativos (Fig. 5, no 1-7). La datación propuesta descansa sobre la presencia en diversos contextos, especialmente la UE 101, de platos de engobe rojo con el borde ranurado al exterior ${ }^{7}$, cuencos grises de borde engrosado, una posible versión local de un skyphos con decoración a bandas-, algunas jarras que versionan las conocidas como neck amphora o "Cruz del Negro” y ánforas locales del T-10121 y quizá T-10221. En conjunto, y apoyados por dos dataciones radiocarbónicas de muestras tomadas en las UUEE 101 y 104, estos elementos parecen situar con cierta precisión los primeros pasos del establecimiento en la segunda mitad del siglo VI a. C., probablemente en un proceso paralelo al de la fundación insular de alfarerías, como se ha documentado ampliamente en el caso de Camposoto (Ramon et alii 2007).

La etapa comprendida entre la construcción del Edificio A y su abandono (Subfase I-b) está deficientemente caracterizada en cuanto a sus facies materiales, debido a que muy pocos depósitos de este periodo se conservaron íntegros, dada la dinámica de reutilización y de reocupación sucesiva. Sin embargo, los argumentos disponibles permiten entrever la preeminencia de los ítems de fabricación gadirita frente a las importaciones, probablemente con un predominio cuantitativo de las típicas ánforas salsarias del grupo T-11213 (Fig. 5, no 8-11) y T-11214/5, limitándose las importaciones a algunos ejemplares griegos orientales. La vajilla en estos estratos se reduce fundamentalmente a platos con engobe rojo al interior, de borde ancho, y cuencos con similar tratamiento (Sáez 2015), siendo el barniz negro ático casi testimonial, apenas algún ejemplo de inset lip cup o incurving rim bowl. Son frecuentes sin embargo los cuencos carenados y hemisféricos en pastas oxidantes con bandas pintadas o sin tratamiento, junto a algunos cuencos de pasta gris y jarras medianas también decoradas con los característicos motivos a bandas rojo/negro. Además de un buen número de tapaderas, el procesado alimentario se habría realizado esencialmente en ollas globu-

\footnotetext{
7 Apuntados como una suerte de "fósil-guía" en los horizontes materiales del siglo VI a. C. en el yacimiento gaditano del Teatro Cómico (López Rosendo et alii 2018), algo ya sugerido en trabajos anteriores a partir de la información publicada de Castillo de Doña Blanca y la necrópolis gadirita insular (Sáez 2015).
} 


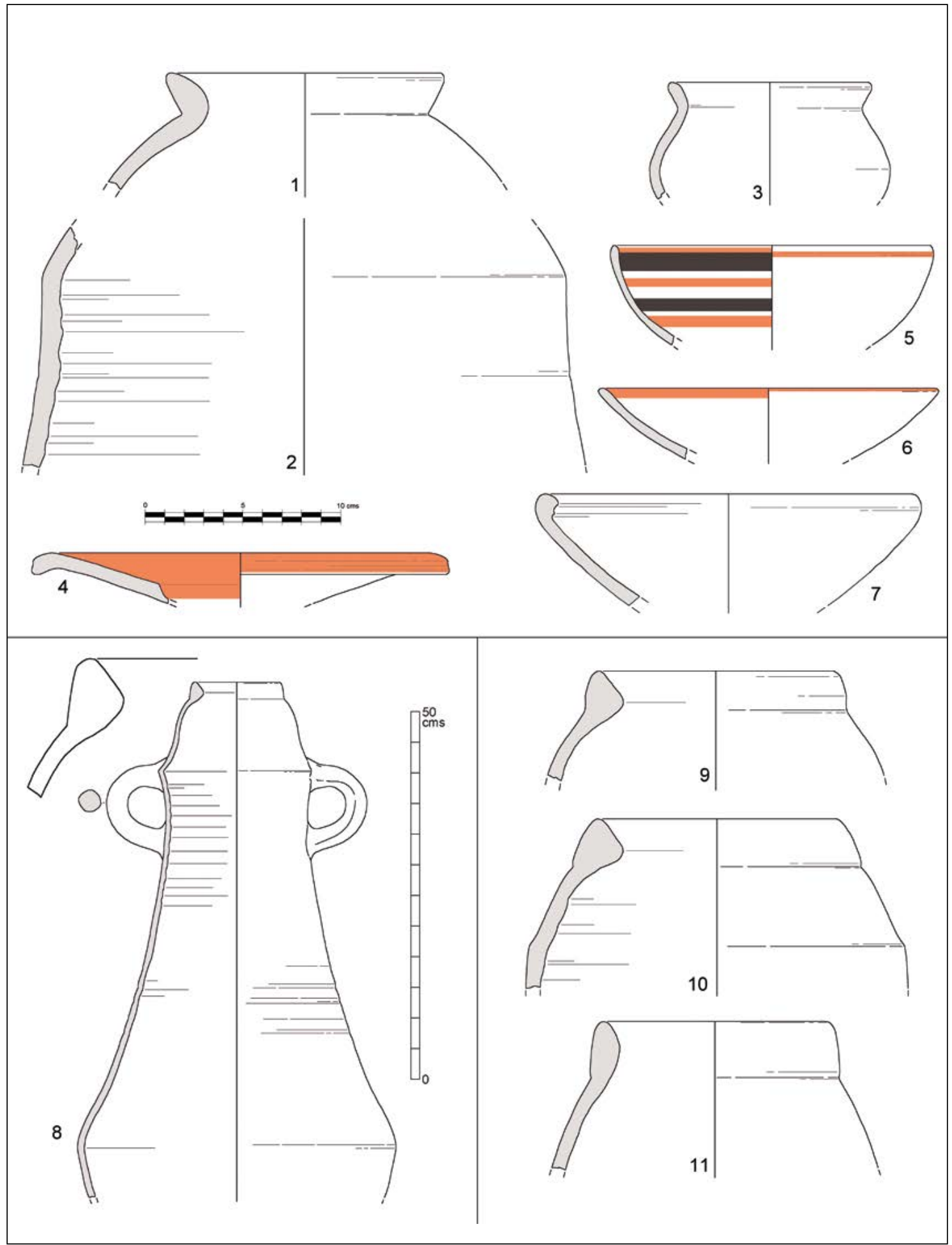

Figura 5. Materiales cerámicos correspondientes a las Fases I-a (1-7) y I-b (8-11) de Puerto-19. Arriba, contexto conformado por ánforas T-10121 (1-2), una olla globular de pequeñas dimensiones (3), un plato de engobe rojo (4), cuencos pintados (5-6) y en cerámica gris (7); abajo, ánforas del tipo T-11213 de la UE 129 (8) y del área excavada en 1997 (9-11) (elaboración propia). 
lares con el labio vuelto al exterior y dotadas de incisiones en el inicio del cuerpo, tipo DIVa1-2 del taller de Camposoto (Ramon et alii 2007).

Los materiales asociados a las fases tardías de actividad (Fase II) proceden sobre todo de grandes basureros situados en las inmediaciones del Edificio B, especialmente de la UE 136, acumulación de vertidos arrojados hacia las cotas inferiores de la duna. Estos estratos depositados sucesivamente en capas de espesor variable muestran en sus repertorios materiales una continuidad formal que no permite discernir la existencia de una cesura cronológica significativa entre subfases. Destaca el gran número de ánforas y de vajilla de mesa (Fig. 6), además de un notable conjunto de cerámicas comunes.

El grueso del material de la Fase II estaba constituido por restos cerámicos de una variada gama de clases y morfologías, mostrando un elevado índice de fragmentación. Entre las ánforas, como parece lógico, son dominantes las fábricas propias de la bahía, especialmente variantes del tipo T-12111 (Fig. 6, n 1-3) y del T-8211 (Fig. 6, no 4-5); asimismo, cabe destacar la gran abundancia de ejemplares procedentes del área turdetana inmediata -campiña gaditano-xericiense, Guadalete, Bajo Guadalquivir-, especialmente de los tipos Florido V2, Pellicer D y "Tiñosa"/T-8112 (Fig. $6, n^{\circ} 7-8$ y 9), siendo mucho menos importantes cuantitativamente otras importaciones del área del Estrecho (T-12111) y las ánforas de probable manufactura contestana y ebusitana. Las importaciones mediterráneas incluyeron una significativa cantidad de ánforas púnicas centro-mediterráneas acilindradas (Fig. 6, nº 6), así como algunas producciones magno-griegas y griegas orientales. Destaca un fragmento de asa de ejemplar cartaginés probablemente asociado a formas acilindradas T-4215/T-5231 que portaba una estampilla epigráfica, mientras que en lo que se refiere a la vajilla, también debemos remarcar la existencia de sendos grafitos epigráficos -¿marcas de propiedad?-, grabados bajo la base de un plato de pescado y un small bowl de bordes entrantes ${ }^{8}$.

El resto de cerámicas documentadas en esta fase estratigráfica corresponde a elementos de vajilla, cerámicas de uso doméstico múltiple y utensilios de cocina. En el caso de la vajilla son mayoritarias las formas abiertas, pues se documentaron abundantes muestras de platos y cuencos en engobe rojo (Fig. 6, $\mathrm{n}^{\mathrm{o}}$ 13-16) o pasta gris locales, a lo que se añade un notable número de vasos áticos de barniz negro (Fig.

${ }^{8}$ Estudio realizado por el Dr. J. A. Zamora López, Escuela Española de Historia y Arqueología en Roma, CSIC, incluyendo asimismo en el trabajo otros grafitos y marcas de carácter no epigráfico.
6, $\mathrm{n}^{\mathrm{o}}$ 10-12), incluyendo cuencos de borde entrante, saleros, bolsales, lucernas, etc. En cualquier caso, las formas locales de pastas sin tratamiento o con decoraciones polícromas parciales -bandas- parecen ser las mayoritarias, especialmente cuencos de cuarto de esfera, páteras carenadas o vasos, siendo las formas cerradas -jarras pequeñas y medianas-, mucho menos abundantes. En el menaje de procesamiento de alimentos debemos destacar el elevado número de morteros locales, así como de ollas y cazuelas, tanto modelos tradicionales como formas helenizadas, muchas de ellas mostrando ennegrecidos en las superficies exteriores que denotan un intenso periodo de utilización.

Además, en estos vertidos se documentaron pesas de plomo para redes, anzuelos de bronce y otro instrumental pesquero (Gutiérrez y Giles 2004), que junto a la presencia abundante de malacofauna ilustran con escaso margen de duda la vinculación del yacimiento a la explotación de los recursos marinos en esta segunda fase. Aquí cabe incluir algunos elementos hasta ahora poco conocidos en relación con este tipo de establecimientos secundarios vinculados a Gadir, caso de tres ejemplares de caracolas Charonia lampas que fueron transformadas en aerófonos mediante el recorte de una porción del ápice, mostrando una de ellas otro orificio (Fig. 7) relacionado con la colocación de una cuerda para su sujeción y/o transporte (Sáez y Gutiérrez 2014). En Puerto-19, todo indica que estas "trompas de Tritón" habrían podido participar tanto de las faenas pesqueras -señalización entre embarcaciones, maniobra, avistamiento de túnidos, etc.-, como en el contexto de un uso agrícola del asentamiento, pastoreo, vigilancia, etc. El estudio de la malacofauna recuperada, especialmente abundante en estos contextos de la Fase II, documenta evidencias de la captura y consumo regular de especies muy comunes en la bahía, navajas, almejas diversas, patélidos, etc.

Los materiales ligados a la fase final de actividad (Fase III), en especial los del vertedero UE 126 (Fig. 8 ), permiten caracterizar un horizonte muy similar al ya descrito para la etapa precedente, con un predominio de las producciones originarias de la bahía frente a las importaciones anfóricas y de vajilla de procedencia miscelánea. Entre las ánforas locales destaca la presencia de T-12111/2, incluyendo alguna miniaturización (Fig. 8, no 1 y 3), T-8211 (Fig. 8, n 2), y significativas cantidades de contenedores turdetanos (Pellicer D) y Tiñosas/ T-8112 (Fig. 8, no 4-5 y 6), alguna T-12111 importada, grecoitálicas y cartaginesas acilindradas (Fig. 8, no 7 y 8). En el apartado de vajilla, es evidente el enorme predominio de las producciones locales en pastas oxidantes sin tratamiento-cuencos, vasos, páteras carenadas- (Fig. 8, no 12-17), con pre- 


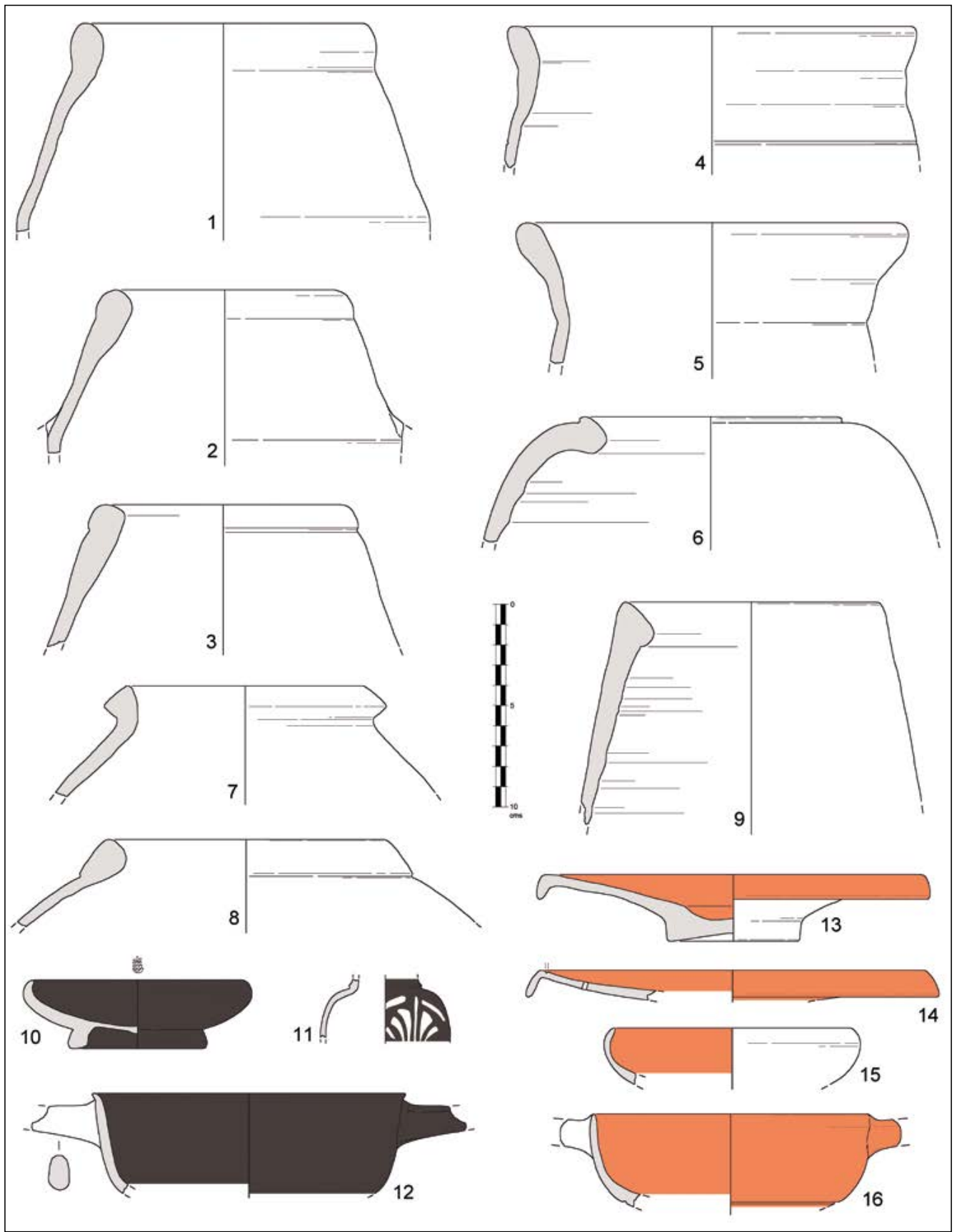

Figura 6. Materiales vinculados a la actividad del asentamiento en la Fase II (vertedero UE 136): ánforas gadiritas de los tipos T-12111 (1-2), T-12111/2 (3) y T-8211 (4-5), ánfora cartaginesa (6), envases turdetanos Pellicer B-C (7) y D (8) y ánfora tipo Tiñosa/T8112 (9); vajilla de mesa de importación griega (10-12) y "barniz rojo" local, entre ellos platos de pescado (13-14), small bowl (15) y bolsal (16) (elaboración propia).

sencia de algunas formas típicas del repertorio inicial de la cerámica de engobe rojo "tipo Kuass" (Fig. 8, no 9-11), plato de pescado, small bowl, bolsal (Niveau de Villedary y Sáez 2016). Destaca el aumento cuantita- tivo de morfologías como jarras medianas sin asas y con bordes apuntados, o pequeñas jarritas tipo olpe (Fig. 8, $\mathrm{n}^{\mathrm{o}}$ 18-19), siendo en este caso los elementos destinados a la preparación y cocción de alimentos 


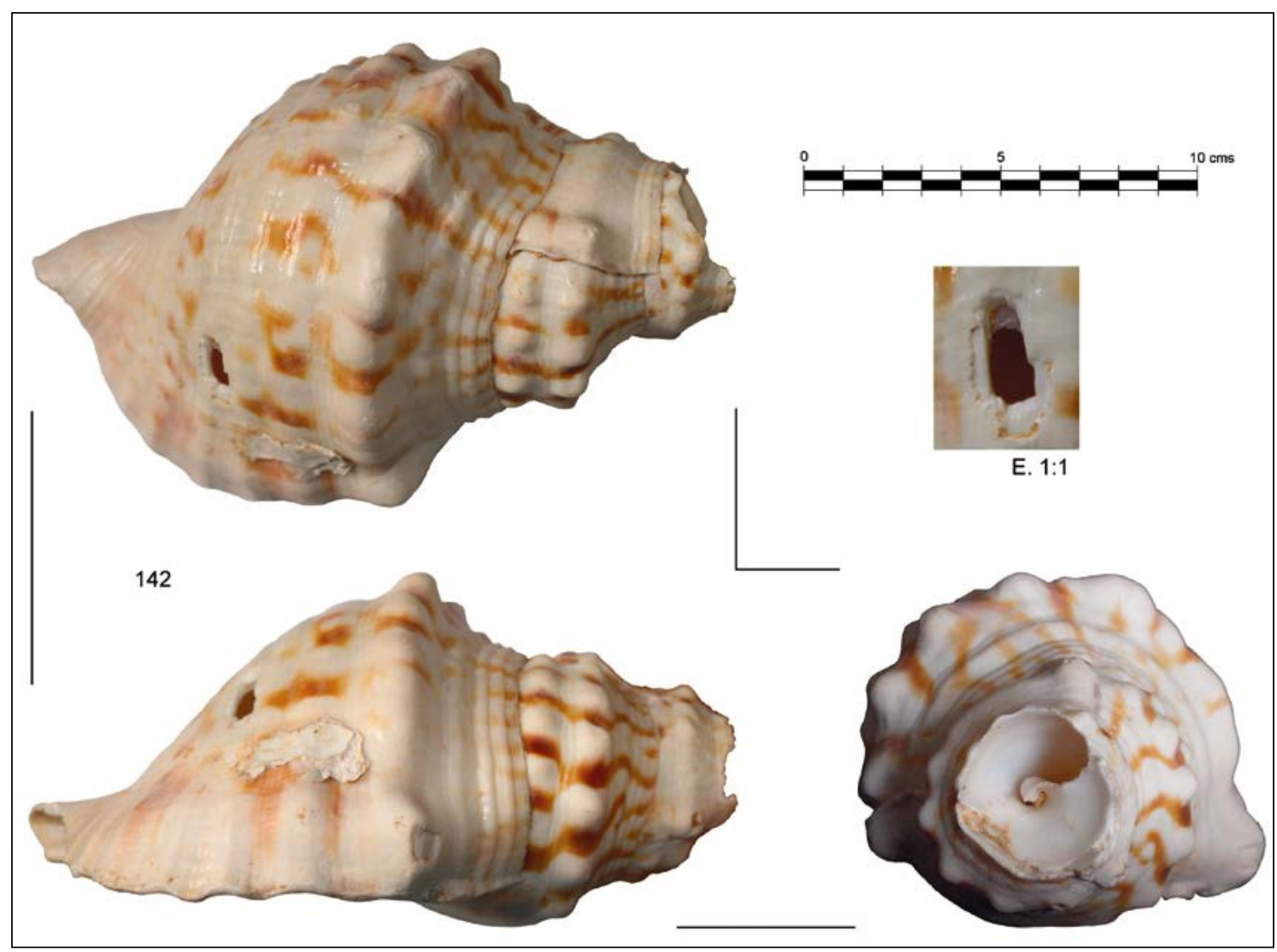

Figura 7. Aerófono fabricado a partir de una caracola de la especie Charonia lampas ( $\mathrm{n}^{\mathrm{o}}$ inv. 142) recuperada en la UE 114 de Puerto-19. Se aprecia en la foto de detalle la perforación taladrada intencionalmente en la concha, así como el ápice serrado (fotografía A. M. Sáez Romero).

más escasos y tipológicamente limitados a las ollas (Fig. 8, n⿳0 20-21), todas ellas con formas características del repertorio local del siglo III (Sáez 2008, 2015). Otra caracola preparada como aerófono, así como anzuelos de bronce y abundante malacofauna, insinúan que esta fase final también tuvo una estrecha relación con la explotación de los recursos marinos.

En definitiva, se trata de un gran cúmulo de elementos que habían quedado completamente inéditos en las informaciones preliminares publicadas hasta 2008 y que gracias al proyecto desarrollado, añade gran detalle y amplitud de matices a una secuencia tremendamente interesante para la lectura de las actividades conserveras gadiritas, dada la parcialidad de los datos publicados hasta ahora del resto de yacimientos similares descubiertos en la campiña costera portuense. El avance que representa Puerto-19 deberá ser ahora complementado y cotejado con otros muchos yacimientos gaditanos directamente relacionados con esta problemática que aguardan aún inéditos o apenas parcialmente publicados, destacando particularmente el caso de Las Redes, dada su proximidad geográfica y las evidentes similitudes en cuanto a su planta y secuencia de actividad (Muñoz 2012).

\section{CONCLUSIONES Y APUNTES PARA EL FUTURO}

Como señalamos en la introducción de este trabajo, el estudio de los materiales y de la secuencia de Puerto-19 se ha desarrollado en el marco de un esfuerzo más ambicioso de acercamiento a la problemática de la "economía conservera" gadirita que ha involucrado a un número bastante más elevado de yacimientos salazoneros y alfareros y ha permitido elaborar una mirada global sobre múltiples aspectos relacionados con estas actividades marítimas de tipo extractivo-productivo y comercial. Basándonos en la nueva documentación generada por el proyecto, y considerando los datos específicos de Puerto-19 como uno de sus pilares fundamentales, es posible ofrecer 


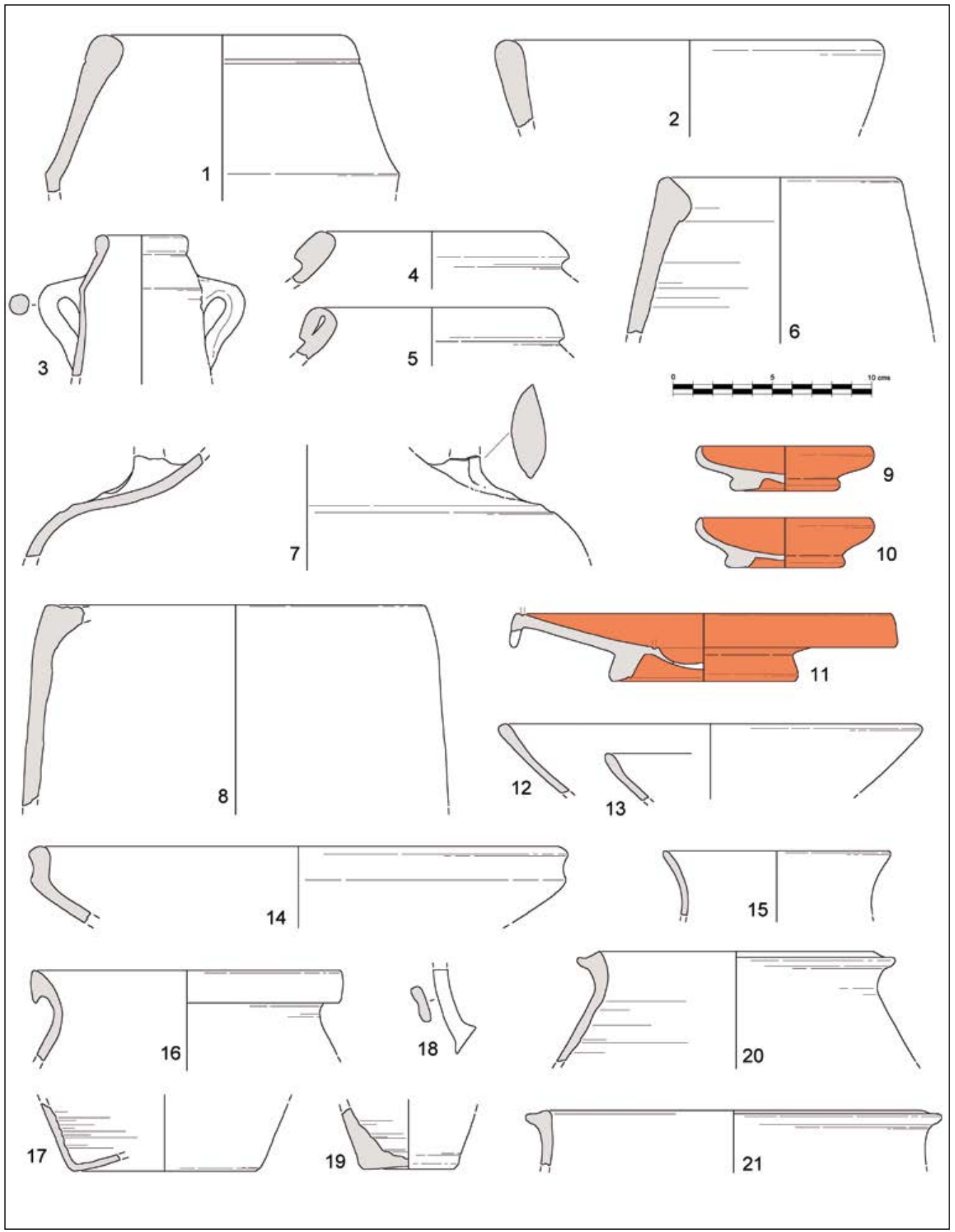

Figura 8. Materiales cerámicos de la Fase III de Puerto-19 (UE 126): ánforas locales tipo T-12111/2 (1), T-8211 (2) y versión en miniatura (3), e importaciones turdetanas (4-5), tipo Tiñosa/T-8112 (6), grecoitálica (7) y cartaginesa (8); asimismo, cerámicas “tipo Kuass" locales (9-11), cuencos comunes (12-13), cuenco carenado (14), vaso (15), tinajas medianas (16-17), jarritas (18-19) y ollas (20-21), todas ellas formas típicas de los repertorios del siglo III a. C. avanzado de la zona (elaboración propia).

una síntesis sobre la evolución general del proceso de formación, consolidación, evolución y disolución final de la estructura del sistema económico y territorial púnico que alumbró y dio sentido a este tipo de instalaciones. Fijaremos nuestra atención exclusivamente sobre el caso gaditano, remitiendo a otros trabajos (García y Ferrer 2012; Sáez 2014; Sáez y García 2019) para una visión ampliada al contexto del área 
del Estrecho y sus relaciones a escala mediterránea (Moya Cobos 2017).

\section{I. P-I9, LAS SALAZONES Y EL MODELO DE POBLAMIENTO DE LA BAHÍA EN ÉPOCA PÚNICA}

La pesca a gran escala, tanto de altura como de bajura, y la salazón de las capturas debieron ser tecnologías orientales llegadas prontamente al Extremo Occidente junto a otros avances determinantes para cambiar las relaciones del hombre con el medio, acelerando y optimizando su explotación, y las posibilidades alimentarias y de progreso demográfico de las comunidades que controlaban el acceso a dichos recursos. Los indicios en este sentido son cada vez más abundantes y explícitos, relegando la tradicional hipótesis de un papel subsistencial u oportunista de la pesca y la comercialización de sus derivados en el contexto de las actividades económicas arcaicas de los fenicios del Extremo Occidente. Como señalamos en trabajos anteriores (Sáez 2011, 2014), los restos de envases anfóricos con contenidos ícticos hallados in situ o los edificios íntimamente vinculados a tareas pesqueras y artesanales datados entre los siglos IX a VI a. C. y distribuidos por toda la geografía regional dejan poca duda de este desarrollo temprano de la fabricación y comercio de derivados piscícolas en los centros costeros de la región, aunque aún está por clarificar su volumen, peso económico y grado de "industrialización" de las infraestructuras. Los apoyos arqueológicos en la bahía gaditana para analizar la pesca fenicia colonial y su posible relación con una "industria conservera" posterior han crecido en los últimos años a partir de recientes excavaciones y del planteamiento de algunas sugerentes hipótesis interpretativas (Roselló y Morales 1994; Bernal et alii 2014a y 2014b, entre otros).

Al igual que sucede con la producción cerámica y por tanto de ánforas de transporte, estas actividades pesquero-conserveras iniciales en la bahía se insertan en un modelo de poblamiento y económico netamente diferenciado del desarrollado a partir del siglo VI a. C., por mucho que puedan observarse nexos entre ambas fases a muchos niveles, por ejemplo, en la tipología y tecnología de las cerámicas ${ }^{9}$. En los últimos años se ha destacado la existencia de cambios sustanciales en la estrategia territorial desarrollada por $\mathrm{Ga}$ -

\footnotetext{
9 Una interesante perspectiva apoyada en estudios arqueométricos la ofrece la tesis doctoral de P. Johnston, defendida en 2015, "Pottery Production at the Phoenician Colony of El Castillo de Doña Blanca (El Puerto De Santa María, Spain) C. 750-550 BCE", Harvard University, Graduate School of Arts $\&$ Sciences.
}

dir a partir de esta fase, en contraste con lo conocido para la etapa arcaica (Botto 2014; Ruiz Mata 2016) ${ }^{10}$. Entre ellos destacan la ordenación definitiva del territorio insular y su aprovechamiento para fines agrícolas, conserveros, alfareros, funerarios y de culto, o la desaparición de la red de aldeas dispersas de "tipo indígena" que habían caracterizado las campiñas continentales durante la etapa arcaica.

El siglo VI a. C. fue para la bahía gaditana una etapa tremendamente compleja, un momento de transición decisivo entre la fase colonial y la consolidación del absoluto protagonismo del elemento urbano y de las ciudadanías, que conllevaría una transformación de las fórmulas de relación y asentamiento dominantes en la etapa anterior. La consolidación definitiva de este proceso se realizaría entre el final del siglo VI y los inicios del V a. C., desarrollándose casi paralelamente no solo en ambientes netamente fenicios sino también ampliamente en el mundo indígena circundante, modificando sustancialmente los parámetros de interacción socio-económica y territorial entre ambas esferas. En el caso gaditano, aunque no hay fuentes que permitan adentrarse con ciertas garantías en el resbaladizo terreno de las jerarquías o dependencias políticas, parece indudable que los tres principales núcleos residenciales, Cádiz, Castillo de Doña Blanca y Cerro del Castillo, habrían quedado ahora integrados en un mismo sistema territorial unitario (regido por las oligarquías gadiritas) que extendía su acción directa por los rebordes continentales de la bahía y parte de los valles del Guadalete e Iro, colindando con potentes entidades estatales como Asido o Asta. Todo ello habría generado no solo unas excelentes plataformas para la extracción-transformación-producción de vino, aceite, sal o salazones sino que asimismo configuraba un potente mercado interno local-regional, basado en la dualidad costa-interior y costa-costa, que ofrecía un marco propicio para el incremento sostenido de la demanda alimentaria.

Este factor, combinado con una creciente demanda de los mercados internacionales, llevó al rápido desarrollo de una potente industria pesquero-conserveraalfarera, generando un modelo de explotación del medio y de implantación territorial completamente diferenciado del arcaico, y que multiplicaba exponencialmente el potencial productivo local acorde al paralelo incremento de la demanda, en volumen y posibilidades de lograr una balanza positiva en la ecuación

10 A ello pueden sumarse cambios significativos en los rituales y tipologías funerarias locales (un ejemplo reciente en Belizón y Sáez 2016; asimismo, Niveau de Villedary y Gómez 2010), o en la proyección exterior del asentamiento, tanto a escala regional como internacional, evidenciada por la distribución de sus ánforas (Ramon 1995). 
valor-precio. Se trataría, quizá como en el caso del vino o del aceite, de un proceso de desarrollo económico no directamente motivado o dependiente de la denominada "crisis de los metales" (Fernández Jurado 2006), sino sobre todo impulsado por los nuevos modelos de gestión de los territorios urbanos, de una mayor interacción de las rutas de comercio regionales con las grandes autopistas marítimas mediterráneas del momento, y con cambios generales en la dieta y la cocina de buena parte del mundo conectado por dichas arterias y mercados.

Gadir fue un asentamiento colonial beneficiado por esta deriva hacia lo urbano al final del periodo colonial y la reorientación de su economía hacia estos sectores debió ser una operación rápida y sin retorno comandada por las élites oligárquicas protagonistas de la expansión comercial ultramarina. Ello permitió a la nueva ciudad una resuelta expansión económica y una fijación igualmente veloz y eficaz de su nueva identidad, cimentada esencialmente en el culto a Melqart/Astarté y en las empresas marítimas. Al contrario de lo observado hasta el momento para la etapa arcaica, el registro de la bahía gadirita de época púnica es desbordante tanto en lo referido a contextos artesanales como funerarios, siendo menos conocida la evolución de sus áreas urbanas y sus principales santuarios. El estatus urbano debió comportar la fijación de un hinterland territorial estable y ordenado física y jurídicamente que se extendió por todo el alargado territorio insular desde la isla de Erytheia hasta el templo de la divinidad tutelar, englobando en este espacio paisajes muy variados entre los que se incluían costas con unas destacadas aptitudes para diversas modalidades pesqueras y amplias llanuras intermareales favorables para el desarrollo de salinas (Fig. 9).

De este modo, dentro del sistema productivo-territorial diseñado por los gadiritas en las postrimerías del siglo VI a. C., salinas, alfares y saladeros de pescado ocuparon un lugar destacado, abarcando una buena parte de la superficie de la "chora" tanto en el ámbito insular como de la costa continental de la bahía. Recursos como la sal, a través de la explotación de las amplísimas áreas marismeñas diseminadas por todo el entorno de los estuarios del Guadalete y del Iro, y los esteros fangosos que rodeaban parte de las islas, debieron ser algunos de los aglutinantes más destacados de esta economía púnica de la bahía gaditana. Por el momento, ningún dato indica que existiesen en esta etapa de los siglos V-III a.C., "asentamientos mixtos" que combinasen saladeros y alfarería en una misma infraestructura. Así, el grueso de la producción cerámica, incluidas por supuesto las ánforas de transporte, parece que fue desarrollado en la denominada isla de Antipolis, o en todo caso en ámbito extraurbano insular, en convivencia con los espacios funerarios.

Los saladeros se ubicaron, según la documentación arqueológica disponible, volcados al mar aunque no siempre en la primera línea de costa. Se han excavado o detectado en prospección ejemplos de estas instalaciones de época púnica tanto en la costa oceánica de la isla gaditana, desde los arenales de Kotinoussa hasta Sancti Petri (Sáez 2014), como probablemente en toda la costa septentrional del saco exterior de la bahía, es decir, entre las actuales Rota y El Puerto de Santa María (Ruiz et alii 2006; López y Ruiz 2010).

En la parte insular de este entramado conservero la evidencia empírica disponible ha proporcionado excelentes referencias sobre las características de los saladeros gadiritas en la parte norte de la Kotinoussa, en puntos como Plaza de Asdrúbal (Bernal et alii 2014b), San Bartolomé/Chinchorros (Sáez y Lavado 2019) o Huerta del Obispo (Pajuelo y López 2016), donde ha sido posible exhumar y estudiar edificios y áreas de actividad/vertido similares a las documentadas en la costa portuense, incluyendo además en algunos casos el estudio de los restos faunísticos. Otros indicios por ahora más sutiles sugieren que estas actividades haliéuticas debieron extenderse a otros puntos de las costas occidentales de la isla gaditana, y en especial, en el tramo situado entre Torregorda, la playa de Camposoto y Sancti Petri, donde pesquerías, almadrabas y saladeros debieron flanquear al propio santuario de la divinidad tutelar (Sáez y Díaz 2012). Otro tanto cabe sospechar del entorno de los canales portuarios septentrionales, zona que más tarde albergaría grandes cetariae y alfares romano-imperiales (Expósito 2007; Bernal et alii 2008), y que, como ya se ha adelantado, también han suministrado indicios pesqueros de época arcaica.

Por su parte, los contextos y estructuras de las Fases I-III de Puerto-19 (fines del siglo VI a fines del III a.C.), permiten ilustrar estratigráficamente lo que debió ser una dinámica generalizada entre los asentamientos ubicados en la costa continental. No se aprecian diferencias notables con los ejemplos documentados en la zona insular respecto a las fechas de inicio, tipología de las instalaciones, dimensiones, características tecnológicas o composición de los repertorios muebles, aunque sí en lo tocante a la cronología de abandono tras la conquista romana, puesto que los asentamientos insulares parecen alargar su vida activa incluso hasta momentos tardorrepublicanos mediante sucesivas actualizaciones (Sáez 2014). Junto a Puerto-19, en la costa portuense contamos con las referencias parciales aportadas por puntos como Las Redes (Frutos et alii 1988; Muñoz et alii 1988) o 


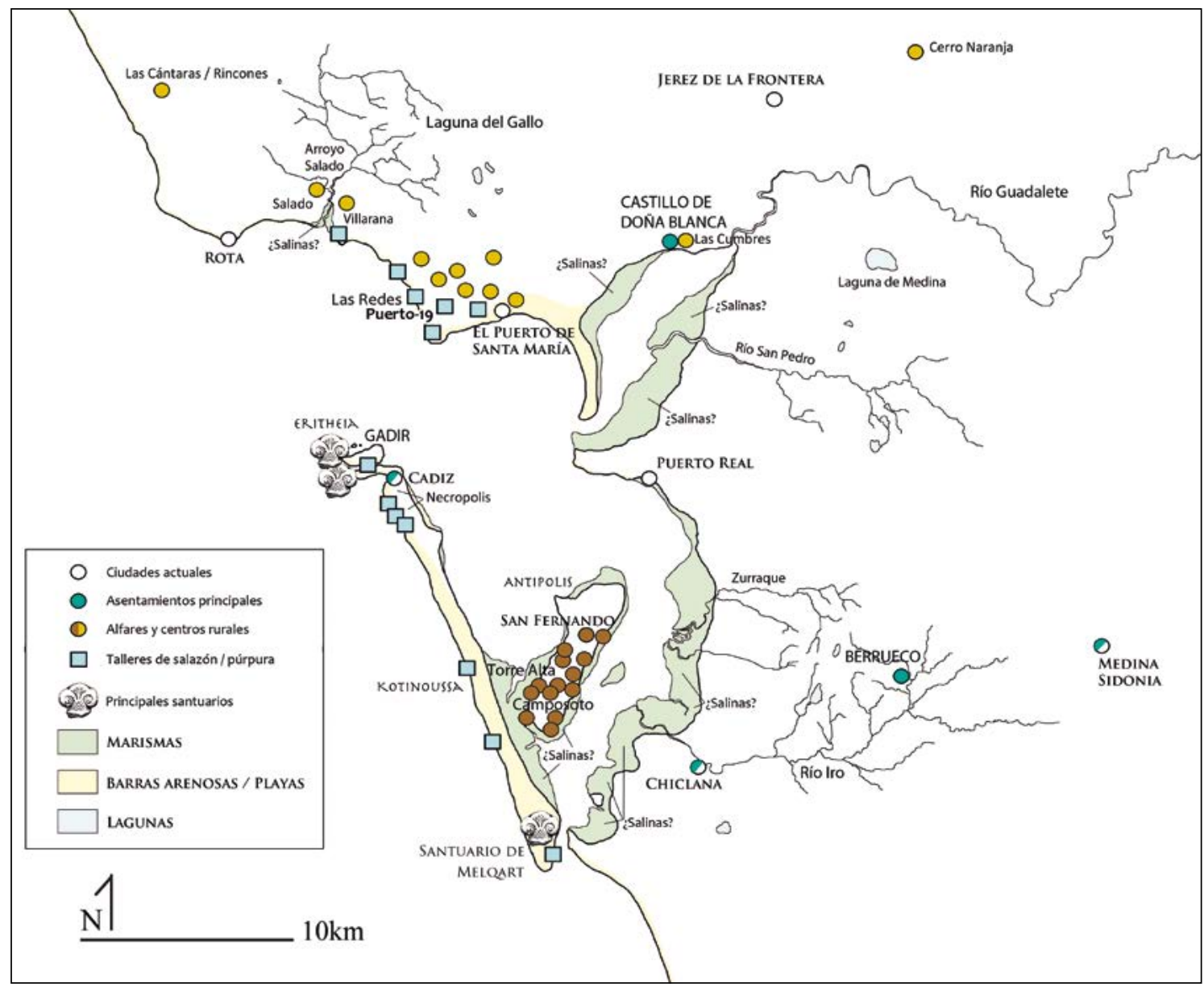

Figura 9. Plano de la Bahía de Cádiz con indicación aproximada de la paleotopografía y la ubicación de los principales yacimientos citados en el texto, característicos del poblamiento de la zona entre el final del siglo VI a. C. y la Segunda Guerra Púnica (elaboración propia).

Puerto-6 (Morales y Roselló 1990), así como con información más incompleta procedente de hallazgos de superficie extendidos entre la actual desembocadura del Guadalete y la costa situada más allá del Salado que parecen indicar que los establecimientos costeros o de vocación costera asentados en la zona debieron ser muy numerosos, más de una veintena según algunos autores (Ruiz et alii 2006; López y Ruiz 2010).

$\mathrm{Si}$ todos ellos pueden identificarse estrictamente con el mismo modelo y dinámica que Puerto-19 es algo que solo un nuevo programa de actuaciones sistemáticas podrá dilucidar, pero las cronologías arrojadas por los materiales disponibles apuntan a un proceso bastante homogéneo. Se ha propuesto que, como en el caso de Puerto-19, la gran mayoría de estos establecimientos habrían desaparecido antes o como consecuencia de la reordenación del territorio subsiguiente a la II Guerra Púnica y la anexión romana (Ibidem), aunque como para el caso del propio CDB este supuesto necesitará de un más amplio soporte estratigráfico para contar con suficientes argumentos.

Las evidencias arqueológicas permiten dibujar una panorámica de la bahía entre la segunda mitad del siglo VI y el tramo final del V a. C. en la cual buena parte de sus costas y superficies intermareales habrían estado salpicadas de saladeros, pesquerías o salinas, y gran parte de su territorio insular habría estado poblado por alfarerías, conformando en conjunto una colosal maquinaria productora de escala mediterránea. Indicadores como la llegada durante el siglo $\mathrm{V}$ a. C. de conservas piscícolas envasadas en ánforas extremo-occidentales a destinos como Atenas, Corinto, Olimpia, Cartago o muchas ciudades centromediterráneas (Docter y Bechtold 2013), y su conjunción con los testimonios aportados por las escasas referencias literarias preservadas (López Castro 1997; García y 
Ferrer 2012), permiten afirmar que la actividad conservera fue uno de los pilares que cimentaron una fase de enorme esplendor económico.

El saladero de pescado de la Fase I de Puerto-19 -Edificio A y "área de trabajo" del sector excavado en 1997 (Fig. 10)- se corresponde a la perfección con esta dinámica económica, y quizá sea una de las versiones locales de una tipología de instalaciones conserveras propias de este horizonte de prosperidad del negocio. La interacción con la orilla continental no está totalmente clarificada en términos de dependencia política, aunque probablemente ambos grupos de saladeros pertenecieron a un afinado sistema económico unitario. Desde nuestra perspectiva actual, es probable que la fundación y fase inicial de Puerto-19 puedan interpretarse como parte del proceso de crecimiento y fijación del territorio de Gadir durante el siglo VI a. C. (Niveau de Villedary 2015), que habría dado lugar a una suerte de "colonización" de esta zona situada entre la costa de la bahía, CDB y Asta, en la cual seguramente se habrían desarrollado tanto saladeros como asentamientos de orientación esencialmente agrícola.

Las siguientes fases arqueológicas del yacimiento encuentran idéntico acomodo en el desarrollo general de la estructura económica y territorial gadirita durante los siglos IV-III a. C., y responden también al esquema de evolución observado en los alfares datados entre los siglos VI-II a. C. (Sáez 2008 y 2014). En estos últimos, al igual que se ha destacado para la necrópolis (Muñoz 2008), el siglo IV debió suponer un periodo de recesión y austeridad, que en algunos casos llevó a abandonar -al menos momentáneamente-, las instalaciones y en otros obligó a reducir su tamaño y reaprovechar los hornos de la centuria anterior poniéndolos de nuevo en uso o em-

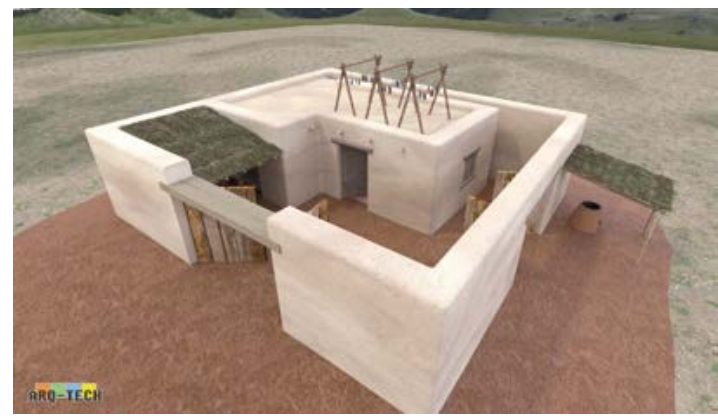

Figura 10. Propuesta de recreación tridimensional del Edificio A de la Fase I-b de Puerto-19, a partir de los indicadores arqueológicos muebles e inmuebles estudiados en el proyecto. El entorno, no incluido en este avance gráfico, se correspondería predominantemente con dunas y pinares (modelo digital desarrollado por Ricardo Belizón, ARQ-TECH. Arqueología y Patrimonio). pleando sus materiales para construir otros nuevos. Ejemplos muy ilustrativos se han documentado en talleres como Camposoto (Ramon et alii 2007) o calle Real (Lavado y Sáez 2009), y se enmarcan en un contexto de recesión económica y amplias transformaciones en los repertorios anfóricos fabricados. Los datos de la necrópolis parecen apuntar en el mismo sentido, desapareciendo los ricos ajuares y las tumbas monumentales de la fase anterior para dar lugar a espacios funerarios más modestos dominados por inhumaciones que en el mejor de los casos fueron cubiertas con sillarejo escasamente labrado y que se acompañaban de objetos menos suntuosos de metal, joyería de plata y bronce, esencialmente, o cerámicas locales.

Las causas de este aparente declive y transformación, que parecen sacudir también CDB (Ruiz y Pérez 1995), resultan complejas aunque probablemente tengan que ver con la desaparición del acceso a los mercados griegos que habían permitido el inmenso beneficio conservero de la centuria anterior y el crecimiento de la competencia tanto centromediterránea (Docter y Bechtold 2013) como regional, en relación con la producción salazonera (López et alii, 2007) lo que provocó la necesidad de reorientar un sistema que durante más de un siglo había primado un monocultivo atunero destinado a unos mercados muy concretos. Sin embargo no cabe hablar de una crisis total, puesto que la dispersión de las ánforas y otros materiales gaditanos hacia el Atlántico o hacia el área turdetana relatan que dicha reorientación se había operado ya hacia la mitad de la centuria, con una "gaditanización" de zonas como el Algarve (Sousa y Arruda 2010). Es probable que tanto alfares como salinas, saladeros y otros negocios directamente dependientes de las rutas en funcionamiento durante el siglo $\mathrm{V}$ a. C. fuesen abandonados total o parcialmente durante los años de "crisis" más álgida y que, posteriormente, la recuperación del sistema ya proyectado hacia Turdetania y el océano, permitiese reactivar algunos de esos mismos puntos a partir de los primeros años o mediados del siglo IV a. C.

Este dramático proceso de supervivencia de Gadir, quizá relacionado con el ascenso de Cartago como potencia mediterránea hegemónica y en permanente confrontación con el mundo griego colonial desde el tramo del siglo $\mathrm{V}$ a. C., puede leerse con facilidad en el registro arqueológico de Puerto-19 a través del tránsito de la Fase I a la II y la construcción del Edificio B sobre los restos del tardoarcaico. Un inmueble más pequeño y sencillo en diseño, que probablemente tuvo un potencial productivo menor que su precedente y que además pudo -al menos en determinados momentos- desarrollar una actividad agropecuaria, como centro de producción vinícola o verdadera "granja" 
multifuncional. Sin embargo, los registros muebles hablan también de un centro secundario que recibía con relativa fluidez importaciones tanto de vajillas de mesa como de alimentos (ánforas), procedentes de mercados extra-regionales, lo que ilustra que la "crisis" del siglo IV a. C. no desconectó por completo al puerto gadirita de las rutas marítimas principales. La vida del Edificio B se prolongó hasta los inicios o mediados del siglo III a. C., pero las causas de su abandono y ruina no han quedado registradas en los contextos preservados y tampoco son sencillas de relacionar, sin un razonable margen de duda, con procesos generales en el asentamiento. No se han detectado discontinuidades de este tipo ni en los alfares ni en los saladeros insulares, por el momento.

En este sentido, solo cabe conjeturar sobre el contexto en el cual insertar la Fase III del yacimiento. La presencia bárquida en Iberia en la segunda mitad del siglo III a. C., durante la cual Gadir jugó un papel de importancia como uno de los principales puertos de referencia para los cartagineses, y el desarrollo final del conflicto con Roma, finalizado en 206 a. C. con la anexión del territorio por parte de la república, parece que pudieron haber alterado sensiblemente los patrones evolutivos de la industria conservera y del modelo de implantación territorial de tradición púnica. En ambas orillas de la bahía se ha observado un fenómeno recurrente de perduración de la actividad artesanal en los mismos puntos desde la oleada de fundaciones tardoarcaicas hasta este periodo de transición, mostrando un patrón estable -como hemos visto, no exento de paréntesis-, que sugiere que la ubicación de las infraestructuras se realizó sujeta a un diseño más amplio que quizá "parceló" amplios sectores del territorio urbano o que al menos ordenó jurídicamente el aprovechamiento de ciertos recursos.

Estos últimos decenios del siglo III a. C., de compleja lectura arqueológica, quizá significasen para el modelo un momento de transformación análogo al observado entre los siglos V-IV a. C., o incluso una ruptura aún más profunda similar a la generada durante el siglo VI a. C. respecto del sistema de relaciones económicas y territoriales arcaico. La falta de fuentes escritas o epigráficas impide atribuir a cartagineses o romanos estas modificaciones sensibles en la tendencia, pero en cualquier caso algunos indicadores arqueológicos son suficientemente elocuentes sobre el desarrollo de procesos diferenciados en la zona insular y la orilla continental: en la isla los talleres cerámicos y los saladeros, con fases sucesivas y reformas, continuaron funcionando en general más allá del 206 a. C., mientras que en el sector continental de la bahía los abandonos fueron generalizados en esta transición de los siglos III-II a. C., incluyendo a los núcleos residenciales principales de ambas cabeceras fluviales, CDB y el Cerro del Castillo en Chiclana.

Aunque no se puede relacionar con actividades bélicas -cartaginesas o romanas-, o con cambios directos en las directrices de ordenación del territorio impuestas tras la conquista, puede señalarse que el abandono definitivo de Puerto-19 estaría reflejando una dinámica generalizada en todo este sector continental, que no parece volver a ser poblado con cierta densidad hasta momentos tardíos del siglo II a. C. Algunos autores han relacionado el abandono de las "factorías" portuenses con un traslado y concentración de la población aguas abajo hasta la desembocadura actual del Guadalete por iniciativa romana, acaso como primera expresión del posterior Portus Gaditanus tardorrepublicano (Ruiz et alii 2006), hipótesis que necesita aún de más amplios argumentos arqueológicos. En cualquier caso, las fosas practicadas sobre los restos del Edificio B testimonian que ya al final del siglo III a. C. la actividad artesanal y quizá la agrícola habían cesado en el lugar, y sugieren una ocupación más esporádica o menos intensa del emplazamiento, quizá usado puntualmente para acampar, como atalaya o simplemente testimoniando las fosas el expolio de materiales constructivos.

\subsection{PeCes Por Pescar. Perspectivas de futuro}

El estudio de los restos documentados en Puerto-19 representa un primer paso hacia un análisis de la industria conservera púnica extremo-occidental (y en concreto de la gadirita) basado en un conocimiento amplio de los registros materiales de los centros productores. La mayor parte de trabajos centrados en esta problemática se habían cimentado sobre informaciones preliminares emanadas de una pequeña parte de las prospecciones y excavaciones realizadas a lo largo y ancho de la bahía, dando lugar así a propuestas en muchos casos de gran interés pero edificadas sobre datos parciales o no del todo fiables. El ejemplo aportado por Puerto-19, en unión a otros yacimientos similares que en la actualidad se encuentran en un proceso de estudio y publicación equivalente, permite explorar nuevas vías de análisis desde una perspectiva renovada y con bases arqueológicas más sólidas, dando lugar a un discurso de evolución histórica de la economía marítima gadirita y de su modelo territorial más complejo y detallado. Estas informaciones proporcionan una primera imagen de gran interés sobre los orígenes remotos de las instalaciones características de una industria que marcó el desarrollo económico y la proyección exterior de la región durante más de un milenio, ofrecien- 
do una perspectiva que hace posible plantear la evolución técnica de la industria conservera hasta enlazar con las mucho mejor conocidas "factorías" de época augustea o imperial.

Queda aún mucho terreno por recorrer en esta senda de mejora de la calidad de la información, permaneciendo por ahora algunas zonas destacadas del litoral, playas atlánticas insulares, costa noreste de la bahía, etc., prácticamente inéditas y sin posibilidad de integrarse con la deseable concreción en el discurso histórico y territorial general, siendo por ejemplo de interés una puesta al día de la publicación del catálogo de yacimientos del área portuense. Paralelamente, yacimientos clave ya excavados en ambas orillas de la bahía, aún se encuentran necesitados de memorias publicadas que complementen los escasos avances dados a conocer tras casi cuatro décadas de investigaciones (Teatro Andalucía o Plaza de Asdrúbal en el área insular, Las Redes en la costa continental).

Nuevos descubrimientos sumados por la Arqueología Preventiva en los últimos años, como los restos de saladeros documentados en Huerta del Obispo (Pajuelo y López 2016) o calle San Bartolomé en Cádiz (Sáez y Lavado 2019), o los indicios recientemente rescatados en diversos tramos del litoral insular, como Camposoto (Sáez y Díaz 2012), subrayan aún con más intensidad la necesidad de dinamizar la entrada de esta información fresca y contextualizada en los discursos interpretativos de la industria conservera de Gadir y de su estructura territorial. Deberá ser este un objetivo a completar en los próximos años, el estudio de las zonas y yacimientos peor conocidos hasta el momento, a fin de perfeccionar el nuevo caudal de datos aportados por puntos como P-19, al mismo tiempo que se ponen en valor otras vías de aproximación complementarias como el fomento de los estudios arqueozoológicos, paleoambientales y geoarqueológicos.

\section{BIBLIOGRAFÍA}

Belizón Aragón, R. y Sáez Romero, A. M. 2016: "Peces Dorados. Un avance sobre recientes descubrimientos en la necrópolis fenicia y púnica de Gadir (Cádiz, España)", Arqueología Iberoamericana 32, 3-10. Disponible en http://laiesken.net/arqueologia/archivo/2016/32/1

Bernal, D., Cobos, L., Marlasca, R., Cantillo, J. J., Vargas, J. y Lara, M. 2014a: "De las fogatas profilácticas púnicas a las chancas romanas. Moluscos y escómbridos en el antiguo Teatro Andalucía de Cádiz", J. J. Cantillo, D. Bernal y J. Ramos (eds.),
Moluscos y púrpura en contextos arqueológicos atlántico-mediterráneos, Cádiz, 179-204.

Bernal, D., Díaz, J. J. y Lavado, M. L. 2008: “Un taller alfarero en el barrio industrial urbano de Gades. A propósito del horno cerámico de la c/ Solano (Cádiz)", Spal 17, 317-322.

Bernal, D., Muñoz, A., Marlasca, R., Cantillo, J. J., Vargas, J. y Lara, M. 2014b: “Atunes ronqueados y conchas de la plaza de Asdrúbal. Novedades haliéuticas en los saladeros gadiritas", J. J. Cantillo, D. Bernal y J. Ramos (eds.), Moluscos y púrpura en contextos arqueológicos atlántico-mediterráneos, Cádiz, 205-228.

Bernal, D. y Sáez Romero, A. M. 2007: "Saladeros y alfares en Gadir. La perspectiva productiva de las ciudades fenicio-púnicas del Extremo Occidente", J. L. López Castro (ed.), Las ciudades fenicio-púnicas en el Mediterráneo Occidental, Almería, 315-368.

Borja Barrera, F., Gutiérrez López, J. M. y Díaz del Olmo, F. 1997: "Fases de dunas durante el Holoceno Reciente en el litoral de El Puerto de Santa María (Cádiz)", Geogaceta 21, 39-42.

Botto, M. (ed.) 2014: Los Fenicios en La Bahía de Cádiz. Nuevas investigaciones. Collezione di Studi Fenici, 46, Roma.

Docter, R. F. y Bechtold, B. 2013: "Two forgotten amphorae from the Hamburg Excavations at Carthage (Cyprus and the Iberian Peninsula) and their contents", Carthage Studies 5, 91-128.

Escacena, J. L. y Vázquez, M. I. 2009: "Conchas de salvación", Spal 18, 53-84.

Expósito, J. A. 2007: “¿Dónde se encuentran las cetariae de Gades? Revisión arqueológica y estado de la cuestión sobre el emplazamiento de las factorías de salazón romanas de la ciudad de Cádiz”. L. Lagóstena, D. Bernal y A. Arévalo (eds.), Cetariae 2005. Salsas y salazones de pescado en Occidente durante la Antigüedad. BAR International Series 1686, Oxford, 367-385.

Fernández Jurado, J. 2006: “Abandonadas las minas, tuvieron que salar el pescado. De la minero-metalurgia tartesia a las salazones romanas", Setúbal Arqueológica 13, 57-68.

Ferrer Albelda, E. 2007: "La bahía de Cádiz en el contexto del mundo púnico: aspectos étnicos y políticos", Spal 15, 267-280.

Frutos, G., Chic, G. y Berriatúa, N. 1988: “Las ánforas de la factoría de salazones de Las Redes (El Puerto de Santa María, Cádiz)", G. Pereira Menaut (dir.), I Congreso Peninsular de Historia Antigua, 1, Santiago de Compostela, 295-306.

Frutos, G. y Muñoz, A. 1996: "La industria pesquera y conservera púnico-gaditana: balance de la investigación. Nuevas perspectivas", Spal 5, 133-165. 
García Vargas, E. y Ferrer Albelda, E. 2001: "Las salazones de pescado de la Gadir púnica. Estructuras de producción", Laverna 12, 21-41.

García Vargas, E. y Ferrer Albelda, E. 2012: "Más allá del banquete: el consumo de las salazones ibéricas en Grecia (siglos V y IV a.C.)", B. Costa y J.H. Fernández (eds.), Sal, pesca y salazones fenicios en Occidente. Trabajos del Museo Arqueológico de Ibiza y Formentera 67, Ibiza, 85-121.

Gutiérrez López, J. M. 2000: “Aportaciones a la producción de salazones de Gadir: la factoría púnicogaditana Puerto 19", Revista de Historia de El Puerto 24, 11-46.

Gutiérrez López, J. M. 2001: “La factoría de salazones púnico-gaditana 'Puerto 19' de Pinar Hondo (El Puerto de Santa María, Cádiz)", Anuario Arqueológico de Andalucía/1997, III, Sevilla, 77-87.

Gutiérrez López, J. M. 2004: 'La factoría 'Puerto 19' (El Puerto de Santa María, Cádiz) y la producción de salazones de Gadir", XVI Encuentros de Historia y Arqueología: Las industrias alfareras y conserveras fenicio-púnicas de la Bahía de Cádiz, Córdoba, 237-262.

Gutiérrez López, J. M. y Giles, F. 2004: “Contexto cerámico de la factoría de salazones púnico-gaditana P-19; Agujas y pesas de red de la factoría de salazones P-19; Útiles de pesca de la factoría de salazones P-19 (anzuelos, ganchos y punta de arpón tipo Macalón)", A. Arévalo, D. Bernal y A. Torremocha (eds.), Garum y salazones en el Círculo del Estrecho, Algeciras, 134-141.

Lavado Florido, M. L. y Sáez Romero, A. M. 2009: "Una nueva área alfarera de Gadir", Boletín de la SECAH. Ex Officina Hispana 1, 12-13.

López Amador, J. J. y Ruiz Gil, J. A. 2007: “Arqueología de la vid y el vino en El Puerto de Santa María", Revista de Historia de El Puerto 38, 11-36.

López Amador, J. J. y Ruiz Gil, J. A. 2010: “Arqueología y etnografía de los recursos marinos en el Puerto de Santa María (Cádiz)", Revista de Historia de El Puerto 44, $1^{\circ}$ semestre, 9-57.

López Castro, J. L. 1997: “Los fenicios occidentales y Grecia”, F. J. Presedo, P. Guinea, J. M. Cortés y R. Urías (eds.), Xaĩpe. II Reunión de Historiadores del Mundo Griego Antiguo. Homenaje al Profesor Fernando Gascó, Sevilla, 95-105.

López Castro, J. L., Alcaraz, F. M., Martínez, V., Moya, L. y Santos, A. 2007: "Una factoría feniciopúnica de salazones de pescado en Baria (Villaricos, Almería, España)", Byrsa VI, 1-2, 9-31.

López Rosendo, E., Pajuelo, J. M., Navarro, M. A., Gener, J. M. y Torres, M. 2018: "Materiales cerámicos del tránsito entre los siglos VII y VI a.C. hallados en las intervenciones arqueológicas rea- lizadas en el Teatro Cómico (Gadir/Cádiz)", Folia Phoenicia, 2, 186-193.

Morales, A. y Roselló, E. 1990: "Puerto 6 (Cádiz): consideraciones osteométricas y culturales de la ictiofauna", Huelva Arqueológica XII, 469-484.

Moya Cobos, L. 2017: Tyria Maria. Los fenicios occidentales y la explotación de los recursos marinos, Sevilla.

Muñoz Vicente, A. 2008: “Topografía y ritual en la necrópolis fenicio-púnica de Cádiz”, F. J. Guzmán, y V. Castañeda (coords.), Vida y Muerte en la Historia de Cádiz, Cádiz, 57-84.

Muñoz Vicente, A. 2012: "Artes y aparejos de pesca fenicio-púnicos en el Mediterráneo Occidental: el ejemplo del Círculo del Estrecho", B. Costa y J. H. Fernández (eds.), Sal, pesca y salazones fenicios en Occidente, Trabajos del Museo Arqueológico de Ibiza y Formentera 67, Ibiza, 33-83.

Muñoz, A. y Frutos, G., 2009: "La pesca y las conservas en la Bahía de Cádiz en época fenicio-púnica", D. Bernal (ed.): Arqueología de la pesca en el Estrecho de Gibraltar. De la Prehistoria al fin del Mundo Antiguo. Monografías del Proyecto Sagena, I, Madrid, 81-131.

Muñoz, A., Frutos, G. y Berriatúa, N. 1988: "Contribución a los orígenes y difusión comercial de la industria pesquera y conservera gaditana a través de las recientes aportaciones de las factorías de salazones de la Bahía de Cádiz”, E. Ripoll Perelló (ed.), I Congreso Internacional El Estrecho de Gibraltar, tomo I, Madrid, 487-508.

Niveau de Villedary, A. M. 2011: "El consumo de vino en la Bahía de Cádiz en época púnica”, Revista de Historia de El Puerto 46, 9-50.

Niveau de Villedary, A. M. 2015: "La estructuración del espacio urbano y productivo de Gadir durante la fase urbana clásica", Complutum 26 (1), 225 242. https://doi.org/10.5209/rev_cmpl.2015.v26. n1.49351

Niveau de Villedary, A. M. y Gómez, V. (coords.) 2010: Las necrópolis de Cádiz. Apuntes de arqueología gaditana en homenaje a J. F. Sibón Olano, Cádiz.

Niveau de Villedary, A. M. y Sáez Romero, A. M. 2016: "The Red Slip Tableware of Punic and Early Roman Gadir/Gades ( $4^{\text {th }}$ and $1^{\text {st }}$ cent. BC): An Update on the so-called 'Kuass Ware'", S. Japp y P. Kögler (eds.), Traditions and Innovations. Tracking the Development of Pottery from the Late Classical to the Early Imperials Periods. IARPotHP Proceedings 1, Wien, 55-68.

Pajuelo, J. M. y López, J. M. 2016: "Calle Huerta del Obispo, no 10 (Cádiz, España)", Red de Excelencia Atlántico-Mediterránea del Patrimonio Pesquero 
de la Antigüedad. Disponible en http://ramppa. ddns.net/cetaria/calle-huerta-del-obispo-no-10

Ramon Torres, J. 1995: Las ánforas fenicio-púnicas del Mediterráneo Central y Occidental, Colección Instrumenta 2, Barcelona.

Ramon, J., Sáez, A., Sáez, A. M., y Muñoz, A. 2007: El taller alfarero tardoarcaico de Camposoto, Monografías de Arqueología 26, Sevilla.

Roselló, E. y Morales, A. (eds.) 1994: Castillo de Doña Blanca. Archaeo-environmental investigations in the Bay of Cádiz, Spain (750-500 BC), BAR International Series, 593, Oxford.

Ruiz Gil, J. A. 1987: "Sondeos arqueológicos de urgencia para la delimitación de las factorías de salazones púnico-gaditanas de El Puerto de Santa María (Cádiz)", Anuario Arqueológico de Andalucía/1986, III, Sevilla, 101-105.

Ruiz Gil, J. A. 1991: “Cronología de las factorías de salazones púnicas de Cádiz”, E. Acquaro, (dir.), Atti del II Congresso Internazionale di Studi Fenici e Punici, vol. 3. Roma, 1211-1214.

Ruiz Mata, D. 1995: "El vino en época prerromana en Andalucía Occidental", S. Celestino, (ed.), Arqueología del vino. Los orígenes del vino en $O c$ cidente, Madrid, 157-212.

Ruiz Mata, D. 2016: "Las ciudades fenicias del Castillo de Doña Blanca y Cádiz durante el siglo VIII a.C. Mi visión actual según los datos recientes arqueológicos", Rivista di Studi Fenici 44 (1), 305 318.

Ruiz Mata, D. 2018: "Varios aspectos sobre el vino y la bodega turdetana-púnica de la Sierra de San Cristóbal, en El Puerto de Santa María (Cádiz)", Revista de Historia de El Puerto 60 (1er Semestre), 9-131.

Ruiz Mata, D. y Pérez, C. J. 1995: El poblado fenicio del Castillo de Doña Blanca (El Puerto de Santa María, Cádiz), Colección de Temas Portuenses 5, El Puerto de Santa María.

Ruiz Mata, D., Ruiz Gil, J. A. y López Amador, J. J. 2006: "La pesca en época prerromana en la bahía de Cádiz (Apéndice sobre las factorías de salazones en El Puerto de Santa María)", I Conferencia Internacional: Historia de la Pesca en el ámbito del Estrecho, I, Sevilla, 269-338.

Sáez Romero, A. M. 2008: La producción cerámica en Gadir en época tardopúnica (siglos -III/-I). BAR International Series, 1812 (2 vols.), Oxford.

Sáez Romero, A. M. 2010: "La producción alfarera y la economía salazonera de Gadir: balance y novedades", Mainake XXXII (II), 885-932.

Sáez Romero, A. M. 2011: "Balance y novedades sobre la pesca y la industria conservera en las ciudades fenicias del área del Estrecho”, D. Bernal Ca- sasola (ed.), Pescar con Arte. Fenicios y romanos en el origen de los aparejos andaluces. Monografías del Proyecto Sagena, 3. Almería, 255-297.

Sáez Romero, A. M. 2014: "Fish Processing and Salted-Fish Trade in the Punic West: New Archaeological Data and Historical Evolution", E. Botte, E. y V. Leitch (eds.), Fish \& Ships: Production et commerce des salsamenta durant l'Antiquité, Bibliothèque d'Archéologie Méditerranéenne et Africaine 17, Aix-en-Provence, 159-174.

Sáez Romero, A. M. 2015: "Imitaciones de vajillas de mesa en la Bahía de Cádiz desde la transición tardoarcaica hasta la época tardopúnica. Actualización de datos y nuevas propuestas", F. J. García Fernández y E. García Vargas (eds.), Comer a la moda. Imitaciones de vajilla de mesa en el Valle del Guadalquivir y sus vínculos atlánticos (s. VI a.C. - VI d.C.), Col-lecció Instrumenta 46, Barcelona, 33-77.

Sáez Romero, A. M. y Díaz Rodríguez, J. J. 2012: "Entre tierra y mar, entre lo púnico y lo romano. Adaptaciones económicas y territoriales en un medio cambiante: algunas notas sobre paleogeografía y sistemas de explotación del hinterland insular de Gadir/Gades", B. Mora y G. Cruz, (coords.), La etapa neopúnica en Hispania y el Mediterráneo centro occidental: identidades compartidas, Sevilla, 259-300.

Sáez Romero, A. M. y García Vargas, E. 2019: "La producción y comercio de ánforas y conservas de pescado en la Bahía de Cádiz en época feniciopúnica. Nuevos datos, métodos y enfoques para viejos debates", A. Álvarez, A. Álvarez-Ossorio, G. Bernard y V. A. Torres (coords.), Fretum Hispanicum. Nuevas perspectivas sobre el Estrecho de Gibraltar durante la Antigüedad. Sevilla, 23-71.

Sáez Romero, A. M. y Gutiérrez López, J. M. 2014: “"Trompas de Tritón' en ambientes productivos de Gadir: el caso de la factoría de salazones de pescado Puerto-19”, J. J. Cantillo, D. Bernal y J. Ramos, (eds.), Moluscos y púrpura en contextos arqueológicos atlántico-mediterráneos, Cádiz, 161-177.

Sáez Romero, A. M. y Lavado Florido, M. L. 2019: "Cremaciones fenicias y un nuevo saladero de pescado púnico de Gadir. Avance de los hallazgos registrados en el área de Los Chinchorros (Calle San Bartolomé, Cádiz)", Habis 50, 49-81.

Sousa, E. y Arruda, A. M. 2010: "A gaditanização do Algarve". Mainake XXXII (2), 951-974.

Recibido: 27-01-2019 Aceptado: 01-07-2019 